\title{
Photophysical processes related to photoadsorption and photocatalysis on wide band gap solids: A review
}

\author{
Vladimir Ryabchuk \\ Department of Photonics, V. A. Fok Institute of Physics, St. Petersburg State University,
}

Ulyanovskaia 1, St. Petersburg, 198504, Russia

\begin{abstract}
During the last two decades, various pathways describing photoexcitation of small molecules' surface reactions at the wide band gap metal oxides and halides $\left(\mathrm{E}_{\mathrm{g}}>3 \mathrm{eV}\right)$ have been recognized. Photogeneration of excitons and free charge carriers may occur in bands of: i) fundamental absorption; ii) extrinsic and intrinsic defect absorption, including those related to surface states; and iii) in UV-induced color centers. Considerable red shifts relative to the fundamental absorption threshold of wide band gap solids have been observed for the spectral limits of surface photoreactions induced in extrinsic absorption bands. This allows thinking about the wide band gap solids as a potential competitors for the relatively narrow band gap photocatalysts. This review discusses the concept of surface photoadsorption (photocatalytic) center while differentiating active and inactive states of the center. Electronically excited defect, surface self-trapped or bound exciton, and the surface defect with trapped photo carrier are considered as the active states of photoadsorption (photocatalytic) centers of different types. The decay pathway of active state determines the lifetime of a photocatalytic center, and in this connection the Langmuir-Hinshelwood kinetic approach is discussed.
\end{abstract}

\section{SUMMARY}

This review will discuss selected topics related to photoinduced chemical reactions in gas/solid heterogeneous systems. The photoadsorption and photocatalytic (photo assisted) reactions of small molecules at the surface of wide band gap solids mainly will be examined. From the chemical point of view, photoadsorption can be considered as the simplest process induced by photons at gas/solid or liquid/solid interface. The variety of photophysical events preceding chemical stages of photocatalytic reaction are often similar (if not the same) to the events characteristic of small molecules photoadsorption. The special emphasis will be on the photoexcitation of solids which precedes the chemical interaction of molecules at illuminating solid surface during photoadsorption and photocatalysis. The concept of surface photoadsorption (photocatalytic) center will be considered in more details in connection with the photoexcitation of a photocatalysts.

\section{INTRODUCTION}

The heterogeneous photocatalysis can be defined as "Photocatalysis taking place at the interfacial boundary between two phases (solid-liquid; solid-gas; liquid-gas)" [1]. Symbolically photocatalytic reaction is expressed by the equation

$$
\mathrm{A}+\mathrm{Cat}+\mathrm{h} v \longrightarrow \mathrm{B}+\mathrm{Cat}
$$

where A, B are reactants and reaction products respectively, Cat is solid photocatalyst (in the case of heterogeneous gas/solid and liquid/solid heterogeneous system) and $\mathrm{h} v$ is the symbol of photon.
In the same manner, photoadsorption defined as "adsorption, typically chemisorption (i.e., a stoichiometric reaction of adsorbate molecules with a solid surface), initiated by light absorbed either by the adsorbate or by the adsorbent," [1] can be presented as

$$
\mathrm{A}+\mathrm{Cat}+\mathrm{h} v \longrightarrow \mathrm{ACat}
$$

where A are adsorbate molecules and ACat are photoadsorbed species. Note, eq. (2) formally is similar to symbolic equation for photochemical reaction, where $\mathrm{A}$ and Cat are reagents and ACat are the reaction products. The similarities between photochemical reaction and photoadsorption will be discussed briefly. Photon absorption by solid photoadsorbent (photocatalyst) will be regarded as the first stage of photoexcitation of heterogeneous system both in a case of photocatalysis (eq. (1)) and photoadsorption (eq. (2)). By definition, photoexcitation is "the act by which an excited state is produced in an entity (molecule or solid photocatalyst) by the absorption of ultraviolet, visible or infrared radiation [1]. In turn, in the light of photoexcitation of photocatalyst, the concept of surface photoadsorption (photocatalytic) center will be discussed in some details.

\section{PHOTOEXCITATION OF WIDE BAND GAP SOLIDS. INTRINSIC AND EXTRINSIC ABSORPTION BANDS. PHOTOELECTRIC ACTIVE AND INACTIVE ABSORPTION (OF LIGHT)}

Photoexcitation of wide band gap solid $\left(E_{g} \geq 3 \mathrm{eV}\right)$ is rather complicated process. In the case of gas/solid heterogeneous systems it often cannot be reduced to 


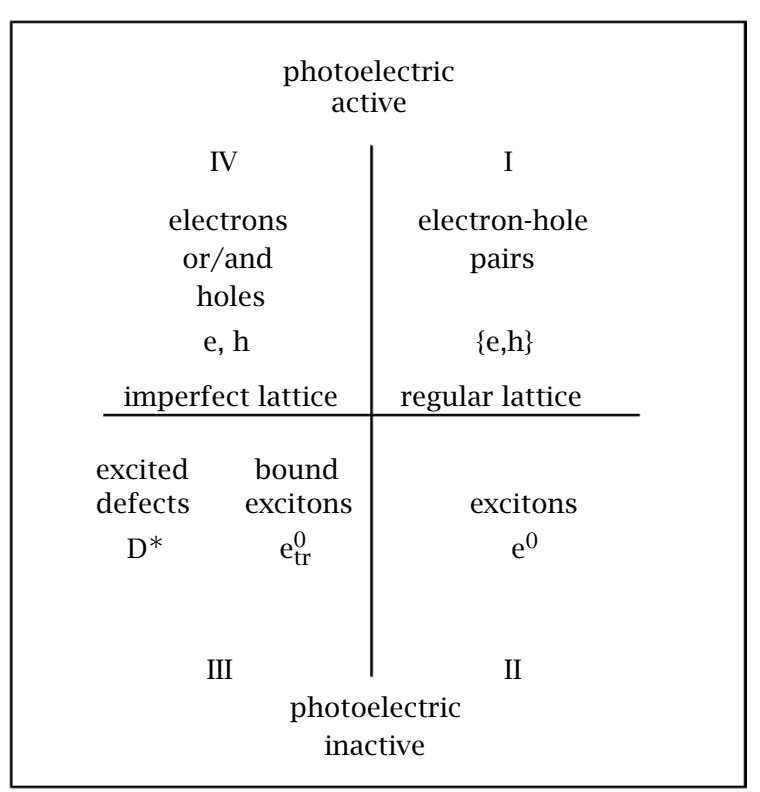

Figure 1. The electronic excitations related to photoelectric active and inactive absorption of light by solid.

well known simplified approach used in the studies of liquid/ $/ \mathrm{TiO}_{2}$ heterogeneous systems. In the latter case to describe the main features of a large number of photocatalytic reactions the consideration of electron-hole pairs generation via band-to-band transitions, reverse recombination of photo carriers and electron transfer through solid-liquid boundary only are often quite enough (see, for example [2]).

It is commonly accepted to tell the difference between the so called photoelectric active and photoelectric inactive light absorption depending on whether or not the free charge carriers appear in solids under illumination (see, for example [3]). On the other hand the absorption of light quanta can be related with regular crystal sites (fundamental or intrinsic absorption) and with crystal imperfections, i.e., with intrinsic and extrinsic lattice defects (see, for example [4-6]). Among the intrinsic defects are vacancies, interstitials and their aggregations (point or zerodimensional defects). Note, regular surface can be considered as two-dimensional defect regarding to threedimensional bulk area of size-restricted solid particle. Foreign atoms, ions and their aggregations in the bulk of host crystal and at its surface constitute the variety of extrinsic defects. The simplified representation of possible types of electronic excitations [3] in solids induced by light absorption of different kinds is shown (Figure 1). The latter go as following:

I. The fundamental absorption related to the transitions between delocalized valence and conduction band states with formation of free electronhole pairs, i.e., separated electrons and holes;
II. The exciton absorption with formation of free bulk excitons $\left(\mathrm{e}^{0}\right)$, i.e., joint electron-hole pairs;

III. The absorption of photons by defects with formation of electronically excited localized states such as electronically excited defects $\left(D^{*}\right)$ and bound or/and self-trapped excitons $\left(\mathrm{e}^{0}{ }_{\text {st }}\right.$, see below);

IV. The absorption of photons following the ionization of defect, i.e., the transitions between localized and delocalized electronic states. The latter belong to conduction or valence band states.

To illustrate the above stated, the absorption spectrum of alkali halide crystal $(\mathrm{KBr})$ containing F-centers (anion vacancies occupied by electrons) is presented (Figure 2). Note, the spectrum is for illustration only, the positions of band maximums shown are only real. The fundamental absorption edge (i.e., the region of "red limit" of I type absorption, Figure 1) is not clearly seen in alkali halides absorption spectra $\left(\mathrm{E}_{\mathrm{g}}=7.35 \mathrm{eV}\right.$ for $\mathrm{KBr}$ ) because it is hidden by exciton bands (the absorption of type II). The fine structure appears in exciton region of absorption spectrum of alkali halides at low temperature (the exciton peaks at 6.71 and $7.18 \mathrm{eV}$ for $\mathrm{KBr}$ ). For further details (see, for example, [7]). Thus one should expect to find the only above-named bands in UV-VIS absorption spectra of super-fine massive alkali halide crystals. At the same time even solely F center introduction into alkali halide crystal gives rise to a few additional absorption bands [8] (Figure 2). The so called $\beta$-band (the peak at $6.44 \mathrm{eV}$ for $\mathrm{KBr}$ ) appears at long-wave side of first exciton band. The bands of this kind are assigned to the so called bound excitons in solids [9]. The latter are considered as excitons weakly bound with lattice defects. The $\beta$-bands in alkali halides arise due to excitons coupled with F centers. Similarly, $\alpha$-bands correspond to excitons localized near the empty anion vacancies (the peak centered at $6.12 \mathrm{eV}$ for $\mathrm{KBr}$ ). The absorption of this kind can be arbitrary ascribed to type III (Figure 1) since bound excitons appear in imperfect crystals. In accordance with hydrogen-like model of F-center [9] the strong F-band (the band maximum at $2.05 \mathrm{eV}$ for $\mathrm{KBr}$ ) corresponds to electronic transition from ground 1 s to lowest $2 p$ excited state of the center, while very week and poorly resolved $\mathrm{K}$-band $(2.36 \mathrm{eV}, \mathrm{KBr})$ is related with the transitions to higher excited states of F-center. Both F and $\mathrm{K}$ absorption should be formally put to the III type (Figure 1). However, the energy gap between the relaxed $2 p$ state of $\mathrm{F}$ centers and the bottom of conduction band is rather small $(0.138 \mathrm{eV}$ for $\mathrm{KBr})$. Therefore free electrons appear in alkali halides under excitation in $\mathrm{F}$ and $\mathrm{K}$ bands via two step photo-thermal ionization of $\mathrm{F}$ centers at sufficiently high temperature. The so called L bands (Figure 2) correspond to transitions from ground 1s state of $\mathrm{F}$ center to delocalized conduction band 


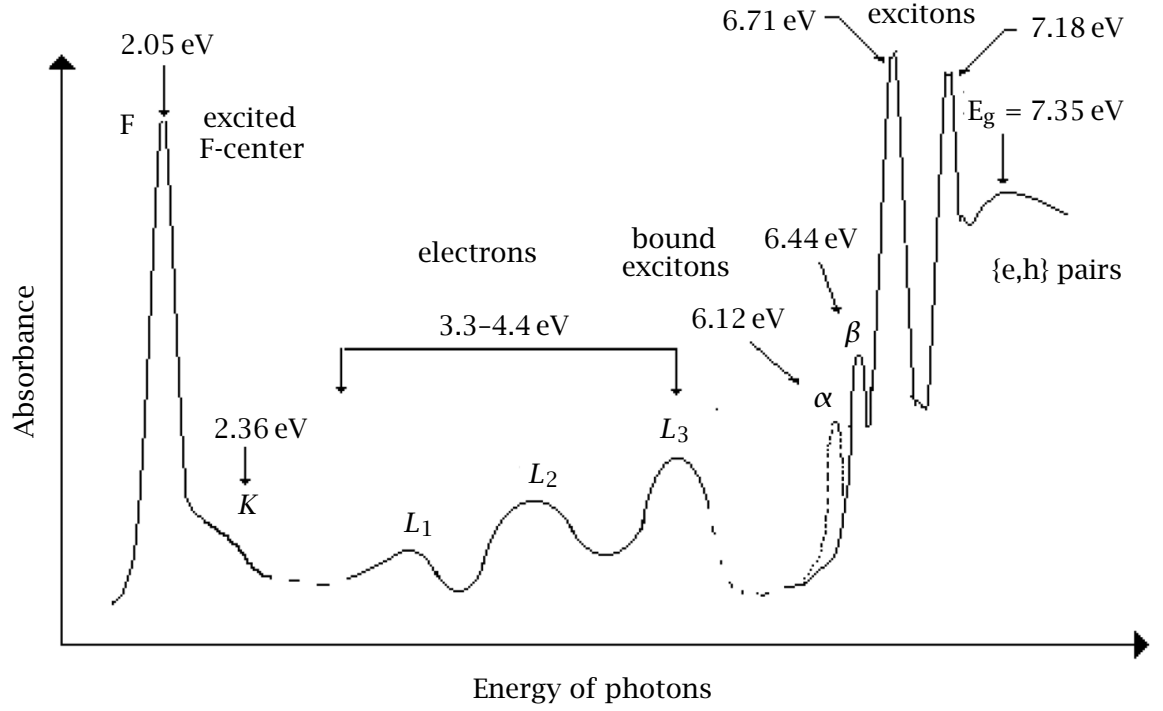

Figure 2. The absorption spectrum of alkali halide crystal with F centers (for illustration only). For example, the positions (eV) of absorption band maximums for excitons and F-center in $\mathrm{KBr}[7,8]$ and corresponding electronic excitations are shown.

states. (The absorption of IV type, Figure 1). The absorption spectrum outlined above becomes more complex if one takes into consideration the F centers perturbed by impurity cations adjacent with anion vacancies, $\mathrm{F}^{-}$centers. i.e., vacancies occupied by two electrons, electrons captured by divacancies and so on $[8,9]$.

The specific absorption originates from the surface states of solid particles $[5,10]$. The surface states correspond to the regular surface sites, crystallite edges, kinks, corner ions and atoms, and with intrinsic surface defects such as vacancies and single ions and atoms. Impurities (foreign atoms, ions and their associations with intrinsic defects) distributed somehow among the bulk and the surface of solid particles as well as adsorbed species also introduce surface states and corresponding absorption bands appear in the overall absorption spectrum extending in UV-VIS region far from the fundamental absorption edge of wide band gap solid.

The photon absorption of all four types (Figure 1) should be taken into account in order to describe a large number of distinctive features of wide band gap photocatalysts which have been ascertained in the studies of gas/solid heterogeneous systems. Nevertheless the photoelectric active absorption of light is considered to be the crucial one in this case, too.

\section{PHOTOEXCITATION. A CASE OF PHOTOELECTRIC ACTIVE ABSORPTION}

It is well known that wide band gap solids $\left(E_{g} \geq 3 \mathrm{eV}\right.$ ) are poor conductors. In contrast with narrow band gap semiconductors the introduction of dopant impurities in the bulk of the insulators does not increase considerably the dark conductivity due to so called selfcompensation effect [11]. For example, when the so called additive coloration of alkali halides is conducted, the super-stoichiometric alkali atoms occupy the normal cation points in alkali halide lattice, the excess electrons are captured by additional thermally induced anion vacancies. Thus the highest occupied electronic level in the crystals (ground state of F center, see above) is located at a distance of no less than $1.5 \mathrm{eV}$ under the bottom of conduction band for the series of alkali halides. In addition, the mobility of carriers for wide band gap solids typically is much lower than that for true semiconductors. However, photoelectric active absorption of light indeed takes place in wide band gap insulators. At least this is evident from the photoconductivity which is known for a large number of insulators [12].

The Scheme (Figure 3) displays some typical events related to photoadsorption and photocatalysis which occur in the bulk in the near surface area [1] and at the surface of wide band gap solids under illumination. The Scheme has been firstly presented in [13]. Whereupon it has been used with minor alteration a few times (see, for example, [14]). Nevertheless, it will be briefly discussed below as well.

The absorption of photons can occur both in the solid bulk (b) or at its surface (s). In turn, at any rate three adjoining and overlapping spectral regions for photoexcitation $[13,15]$ can be distinguished. There are the following:

1) fundamental absorption bands $\left(\mathrm{h} \nu_{1}\right)$ related to band-to-band transitions (type I, Figure 1) in 


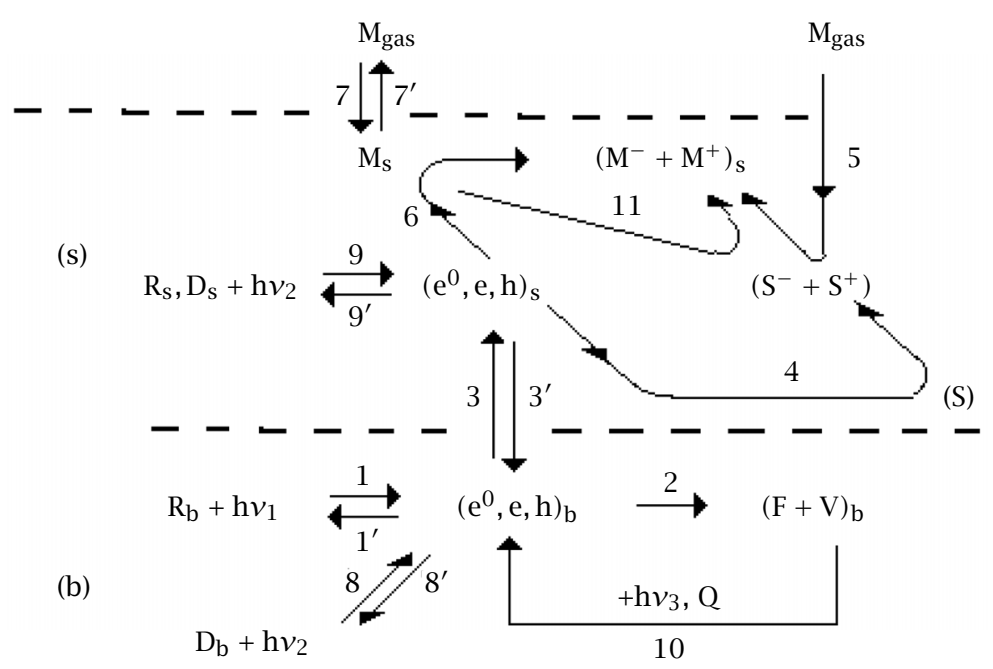

Figure 3. Photoinduced processes in the near surface area (b) and at the surface (s) of wide band gap photocatalyst. From ref. $[13,14]$.

regular crystal bulk $\left(\mathrm{R}_{\mathrm{b}}\right)$. To simplify the discussion the bulk exciton $\left(\mathrm{e}^{0} \mathrm{~b}\right)$ bands (type II) adjoining fundamental absorption edge of the solids are also included in $\mathrm{h} \nu_{1}$ region (see below);

2) extrinsic absorption bands $\left(\mathrm{h} v_{2}\right)$ related to regular surface sites $\left(\mathrm{R}_{\mathrm{S}}\right)$ as well as to various imperfections both in the bulk $\left(\mathrm{D}_{\mathrm{b}}\right)$ and at the surface (D) (type III and IV);

3) color centers absorption bands $\left(\mathrm{h} v_{3}\right)$ related to so called deep traps in wide band gap solids. Deep traps capture photoelectrons and photoholes and retain carriers for sufficiently long time at a certain conditions (see below). To simplify the picture here notations $\mathrm{F}$ and $\mathrm{V}$ relate to any deep trap occupied by photoelectron or photohole respectively. In contrast with other above mentioned defects the color centers appear in the solids due to pre-irradiation. In any case we put the absorption of light in $\mathrm{F}$ and $\mathrm{V}$ color centers bands to type of IV or/and III (see above).

Within the model, the majority of further steps of photoexcitation (Figure 3) following the generation of carriers, can be described as events which include transfer of photocarriers resulting in their trapping by defects except of the band-to-band recombination. In the latter only case the lattice defects do not participate in the process $\left(1^{\prime} 9^{\prime}\right.$, Figure 3$)$

$\mathrm{e}_{\mathrm{b}}\left(\mathrm{e}_{\mathrm{s}}\right)+\mathrm{h}_{\mathrm{b}}\left(\mathrm{h}_{\mathrm{s}}\right) \longrightarrow \mathrm{R}_{\mathrm{b}}\left(\mathrm{R}_{\mathrm{s}}\right)+$ (photons or/and phonons)

However, the efficiency of the recombination (eq. (3)) typically is very low in wide band gap solids. Actually, in a case of nonradiative recombination the relatively large energy of electron-hole pair $\left(E_{g}\right)$ must be changed for the energy of a large number of phonons in manyparticle process, while in a case of radiative (luminescent) recombination the momentum conservation law demands of practically zero sum momentum for recombining electron-hole pair [3]. Thus the alternative recombination of photocarriers via subsequent trapping of electrons (e) and holes (h) and vice versa by so called recombination centers $\mathrm{R}_{\mathrm{c}}$ (not shown, Figure 3 ) is considered as preferable pathway for photo carriers decay under moderate irradiation in imperfect wide band gap solids

$$
\begin{aligned}
& \mathrm{R}_{\mathrm{C}}+\mathrm{e}(\mathrm{h}) \longrightarrow \mathrm{R}_{\mathrm{C}}{ }^{-}\left(\mathrm{R}_{\mathrm{C}}{ }^{+}\right) \\
& \mathrm{R}_{\mathrm{C}}{ }^{-}\left(\mathrm{R}_{\mathrm{C}}{ }^{+}\right)+\mathrm{h}(\mathrm{e}) \longrightarrow \mathrm{R}_{\mathrm{C}}
\end{aligned}
$$

Note, the energy levels $\left(\mathrm{R}^{-}, \mathrm{R}^{+}\right)$of recombination centers typically lay near the middle of band gap and so their thermal ionization can be neglected. Typically the amount (concentration) of $\mathrm{R}_{\mathrm{c}}$ centers in crystals and their ability for the effective trapping of both electrons and holes determine the lifetime of free photocarriers, and so their concentration at a given density of carriers photo generation [3].

The formation of $\mathrm{F}$ and $\mathrm{V}$ centers (2, Figure 3) in the bulk of crystal particle is similar to the first stage of recombination (4). For distinctness, the formation of the $\mathrm{F}$ color center in a commonly accepted sense can be expressed as

$$
\mathrm{v}_{\mathrm{a}}+\mathrm{e} \longrightarrow \mathrm{F}
$$

where $v_{a}$ and e are the symbols of anion vacancy and electron respectively.

The recombination decay of $\mathrm{F}$ centers is similar to the second stage of the recombination via defects 
(eq. (5))

$$
\mathrm{F}+\mathrm{h} \longrightarrow \mathrm{v}_{\mathrm{a}}
$$

The formation and the recombination decay of $\mathrm{V}$ color centers can be expressed by

$$
\mathrm{v}_{\mathrm{C}}+\mathrm{h} \longrightarrow \mathrm{V}
$$

and

$$
\mathrm{V}+\mathrm{e} \longrightarrow \mathrm{v}_{\mathrm{c}}
$$

respectively, where $\mathrm{v}_{\mathrm{c}}$ is the symbol of cation vacancy.

The rates of color centers decay (eqs. (7) and (9)) typically are much lower than the rates of recombination centers decay (eq. (5)). As the result, in contrast with the recombination centers in the states $\mathrm{R}_{\mathrm{C}}{ }^{-}$and $\mathrm{R}_{\mathrm{C}}{ }^{+}$(eq. (4)), $\mathrm{F}$ and $\mathrm{V}$ centers accumulate in wide band gap crystals under illumination, their concentration become comparable in order of magnitude with the initial concentration of trapping centers ( $v_{a}$ and $v_{C}$ in our case) at sufficiently long irradiation time. UV-induced formation of color centers (photo coloration) gives rise to additional bands in absorption spectrum of wide band gap solids such as $\mathrm{F}$ and $\mathrm{K}$ bands for F-centers in alkali halides (Figure 2). The photocolored crystals retain color for a long time after termination of UV irradiation at moderate temperature [8].

The alternative pathway of $\mathrm{F}$ and $\mathrm{V}$ centers decay via their photoionization by actinic light in a coarse of primary illumination $\left(\mathrm{h} v_{1}\right.$, Figure 3$)$ are also reduces the overall rate of color centers formation as well as their ultimate concentration. However, here we focus on the photo bleaching of color centers by long wave light (h $v_{3}, 10$, Figure 3 ) which corresponds to photoelectric active absorption (IV type, Figure 1) of color centers

$$
\begin{aligned}
& \mathrm{F}+\mathrm{h} v_{3} \longrightarrow \mathrm{v}_{\mathrm{a}}+\mathrm{e} \\
& \mathrm{V}+\mathrm{h} v_{3} \longrightarrow \mathrm{v}_{\mathrm{c}}+\mathrm{h}
\end{aligned}
$$

Note, the photo stimulation of only F centers (eq. (10)) typically leads also to destruction of V centers (eq.(9)) and vice versa. On the other hand both free electrons and free holes appear in solid under illumination of colored crystal in overlapping $\mathrm{F}$ and $\mathrm{V}$ absorption bands. (Figure 3, 10). The carriers can also release from the color centers via thermal stimulation (thermal annealing of color)

$$
\mathrm{F}, \mathrm{V}+\mathrm{Q} \longrightarrow \mathrm{v}_{\mathrm{a}}\left(\mathrm{v}_{\mathrm{c}}\right)+\mathrm{e}(\mathrm{h})
$$

In the latter case color centers lose captured carriers due to their interaction with lattice phonons.

Electrons and holes release also from bulk impurities in crystals $\left(\mathrm{D}_{\mathrm{b}}\right.$, Figure 3 ) which adsorb light in extrinsic absorption bands $\left(\mathrm{h} v_{2}, 8,8^{\prime}\right)$. The processes at the surface which correspond to those outlined above for crystal balk are presented (Figure 3) by the excitation of regular surface sites $\left(\mathrm{R}_{\mathrm{s}}\right)$ and any other surface defects $\left(\mathrm{D}_{\mathrm{s}}\right)$.

Whatever the "source" of photoelectrons $\left(\mathrm{e}_{\mathrm{s}}\right)$ and photoholes $\left(\mathrm{h}_{\mathrm{s}}\right)$ the carriers get to the surface (Figure 3, 3, 9). Both Langmuir-Hinshelwood (LH) and Eley-Rideal (ER) types of photoadsorption of molecules $\left(\mathrm{M}_{\mathrm{gas}}\right)$ or the stage of photocatalytic reaction with formation of adsorbed species $\left(\mathrm{M}_{\mathrm{ads}}{ }^{-}, \mathrm{M}_{\mathrm{ads}}{ }^{+}\right)$are presented.

The reactions of LH type are depicted as the trapping of photocarriers (6) by adsorbed molecules $\left(\mathrm{M}_{\mathrm{s}}\right)$ which are at the adsorption equilibrium with molecules in a gas $\left(7,7^{\prime}\right)$. The reactions of ER type are portrayed as sticking interaction (5) of molecules $\left(\mathrm{M}_{\mathrm{gas}}\right)$ with surface defects (centers) $\mathrm{S}^{-}$and $\mathrm{S}^{+}$. The latter generate via trapping of electron and hole by some surface defects S (Figure 3, 4). Hereinafter in a frame of the "photoelectric active absorption" approach $S$ centers will be referred as photoadsorption (or photocatalytic) centers while $\mathrm{S}^{-}, \mathrm{S}^{+}$species will be named active states of photoadsorption (photocatalytic) centers [1]. Reasons for introducing such terms will be clarified below.

\section{PHOTOEXCITATION. A CASE OF PHOTOELECTRIC INACTIVE ABSORPTION}

In accordance with the simplified scheme (Figure 1) the photoelectric inactive absorption induces free (delocalized) excitons in the photocatalyst solid bulk (II, the case of ideal lattice), and leads to formation of the localized electronically excited states of the defects (III, the case of imperfect lattice).

The excitons are virtual particles that describe energy transfer in different condensed systems from solid noble gases and solid hydrogen [16] to molecular crystals and biological systems [17]. The bulk exciton absorption bands corresponding to direct allowed bandto-band transitions can be very strong (the absorption coefficient $\alpha \approx 10^{6} \mathrm{~cm}^{-1}$ ) in semiconductors and insulators. If the transitions are indirect and forbidden, the exciton absorption can be rather weak [18]. Apart from the absorption of photon, excitons may also appear in crystals via electron-hole coupling, for example, in a case of $\gamma$-rays irradiation of the solid. An exciton transfer occurs due to a weak dipole-dipole coupling in the condensed state [19]. The behaviour of excitons, even though they rise in regular lattice, can be rather complicated depending from the nature of the solid.

Free excitons, typically, undergo the annihilation with evolving of photon (radiative decay) or dissociation onto free electrons and holes. The latter may be predominant channel for the exciton decay depending from the exciton binding energy and ambient temperature. The so called self-trapping of excitons occur in some solids under a certain conditions. Excitons can self-trap due to exciton-phonon coupling. In contrast 
with the exciton trapping by defects, the self-trapping is the formation of localized excitons in regular lattice $[18,20]$. At that excitons become immobile (or move by "hopping"), their energy strongly reduces and the relaxation of the neighbor lattice sites changes. The self-trapped excitons (STE) are rather the electronically excited lattice defects than quasi particles. The selftrapping of excitons has been established for a large number of alkali halides and oxides [18, 20, 21]. The STE luminescence often reveals the exciton trapping in solids. For example, a well-known blue emission of silica (broad peak at $2.75 \mathrm{eV}$ ) originates from the tripletto-singlet transition in the STE with decay time $\approx 1 \mathrm{~ms}$ [22].

In addition, the so called decay of excitons onto Frenkel defects pairs (vacancy and corresponding interstitial ion (atom)) in the regular lattice occurs under photoexcitation in exciton absorption bands of alkali halides and some other solids [18, 23]. Such photoreaction is the "solid analogue" of free molecules' photodissociation. In order for the exciton decay to occur a few conditions must be observed, two of them follow from the energy and the momentum conservation laws. The exciton energy must exceed the formation energy of Frenkel pair $\left(E_{\mathrm{ex}}>\mathrm{E}_{\mathrm{F}}\right)$ in a given crystal, and the "lifetime" of the exciton in a given lattice point must be comparable with the period of lattice vibrations ( $\tau_{\mathrm{ex}} \geq \tau_{\mathrm{vib}} \geq 10^{12} \mathrm{~s}$ ). For example, [23] the bulk excitons in alkali halide lattice $\left(\mathrm{e}^{0}\right)$ at the primary stage of the self-trapping process

$$
\mathrm{e}^{0} \longrightarrow \mathrm{e}^{0}{ }_{s t}\left(\mathrm{~V}_{\mathrm{K}} \mathrm{e}^{-}\right) \longrightarrow \mathrm{R}_{\mathrm{b}}+\mathrm{h} v
$$

decay ( $10^{-11} \mathrm{~s}$ time scale): i) onto the F center and the complementary interstitial halogen atom (H center)

$$
\mathrm{e}^{0} \longrightarrow \mathrm{V}_{\mathrm{a}}{ }^{+} \mathrm{e}^{-}(\mathrm{F})+\mathrm{Hal}^{0}{ }_{\mathrm{i}} \text { (H-center) }
$$

and ii) onto the anion vacancy and the complementary interstitial anion (I center)

$$
\mathrm{e}^{0} \longrightarrow \mathrm{V}_{\mathrm{a}}{ }^{+}+\mathrm{Hal}^{-}{ }_{\mathrm{i}} \text { (I-center) }
$$

(The upper index (eqs. (14a) and (14b)) in the notations used above [23] shows the sign of the effective defect charge or its component, while the bottom index indicates the anion (a) or interstitial (i) positions of the defect in the lattice.) When an alkali halide crystal is irradiated with photons free excitons $\left(\mathrm{e}^{0}\right)$ are formed. A self-trapped exciton $\left(\mathrm{e}^{0}{ }_{\mathrm{st}}\right)$ is created (eq. (13)) via free exciton relaxation. The latter process includes the self-trapping of hole component of the exciton $\left(\mathrm{h}^{+} \mathrm{e}^{-}\right)$. The self-trapped hole $\mathrm{h}^{+}{ }_{\text {st }}$ (commonly accepted name- $-\mathrm{V}_{\mathrm{K}}$-center) takes the configuration of halogen $\mathrm{Hal}_{2}{ }^{-}$molecular ion, i.e., a hole ( $\mathrm{Hal}^{0}{ }_{\mathrm{a}}$ ) chemically bound with halogen regular lattice ion $\left(\mathrm{Hal}^{-}{ }_{\mathrm{a}}\right.$ ). Note, the $\mathrm{Hal}_{2}{ }^{-}$species $\left(\mathrm{V}_{\mathrm{K}}\right.$ center configuration) occupies two anion vacancies, the axis of $\mathrm{V}_{\mathrm{K}}$ center aligns along the $\langle 110\rangle$ directions in face-centered alkali halide crystals. At that the distance between halogen atoms for the self-trapped hole $\left(\mathrm{Hal}_{2}{ }^{-}\right)$becomes shorter than that for regular lattice sites. Thus the self trapped exciton can be described as an electron coupled with $V_{K}$ center- $\left(\mathrm{V}_{\mathrm{K}} \mathrm{e}^{-}\right)$. The reactions (eqs. (14a) and (14b)) can be treated as the alternative pathway of exciton relaxation (eq. (13)). For example, the exciton reaction (eq. (14a)) is an isomeric transformation from self-trapped exciton to the F-H pairs. In this case the interstitial halogen atom $\left(\mathrm{Hal}^{0}{ }_{\mathrm{i}}\right.$ or so called $\mathrm{H}$ center) takes the configuration similar to that for self-trapped hole $\left(\mathrm{V}_{\mathrm{K}}\right.$ center). However, in contrast with the self-trapped hole $\left(\mathrm{V}_{\mathrm{K}}\right.$ center configuration) the $\mathrm{Hal}_{2}{ }^{-}$species of $\mathrm{H}$ center type occupies one anion vacancy and interstitial lattice point. The another type of self-trapped exciton transformation is the reaction (eq. (14b)). Note, the reverse reaction (eq. (14a)), i.e., the recombination of neutral Frenkel defects and the reverse reaction (eq. (14b)), i.e., the recombination of charged Frenkel defects both lead to restoration of regular lattice. (For further details see, for example [18, 23]).

The interstitial $\mathrm{H}$ and I species stay immobile in alkali halides lattices only below the $10-50 \mathrm{~K}$. Some polyatomic molecule-like hole centers are produced via secondary reactions of the interstitial defects both in the lattice balk and at the surface of alkali halides at moderate temperature. As a result, additional and even extraordinary surface active sites can be created at the surface of alkali halides by light in comparison to those, created via carriers trapping by pre-existing defects (eqs. (6)-(9)).

The interaction between the excitons and the defects typically leads to the exciton scattering and decay [18]. The reactions of the three following types will be emphasis.

1. The coupling of excitons by defects (D) with formation of electronically excited states of the defects $\left(\mathrm{D}^{*}\right)$

$$
\mathrm{e}^{0}+\mathrm{D} \longrightarrow \mathrm{D}^{*} \longrightarrow \mathrm{D}+\mathrm{h} v+\text { phonons }
$$

Under a certain conditions the $\mathrm{D}^{*}$ states of both intrinsic and extrinsic defects decay with the emission of photons (exciton induced luminescence of defects). In general terms the reaction (15) corresponds to recombination of free photo carriers via recombination centers (eqs. (4) and (5)).

2. The ionization of defects by excitons with the free electron or hole releasing

$$
\mathrm{F}+\mathrm{e}^{0} \longrightarrow \mathrm{V}_{\mathrm{a}}+\mathrm{e}
$$

3. The exciton-defect reactions resulting in the formation of electron (hole) bound with the defect (D) and free hole (electron):

$$
\mathrm{D}+\mathrm{e}^{0} \longrightarrow \mathrm{D}^{-}+\mathrm{h} ; \quad \mathrm{D}+\mathrm{e}^{0} \longrightarrow \mathrm{D}^{+}+\mathrm{e}
$$


The experimental evidence for the reactions (eqs. (16) and (17)) which occur in ionic crystals has been demonstrated a long ago (see, for example, [18, 23]). Recently the theory of the exciton induced ionization of the defects has been proposed [25] in order to describe the exciton decay in conjugated polymers. The reactions are considered as the Auger process, in which the electron (hole) of the exciton occupy the deep defect level while the energy is released to the hole (electron), the defect Auger process for excitons takes place at low exciton density.

The interaction of bulk excitons with the solid surface may be examined in the way similar to that outlined above for exciton-defects interaction in crystal bulk. In general the surface are considered as the bulk exciton sink. The surface recombination and dissociation of bulk excitons damp the exciton induced processes in the near surface area of crystals. On the other hand the excitons, which move from the bulk to the surface may induce the surface chemical reactions. (We do not discuss here resonant energy transport between defects of the same nature such as the rare earth ions in laser crystals which also may be refereed to the photoelectric inactive process [26, 27].)

The absorption of light by solid surface with formation of surface exciton-like excited states (type II, Figure 1) which originate from the regular surface sites and intrinsic surface defects (edges, corners, kinks) may be identified as very significant primary process for photoadsorption and photocatalysis with highly dispersed solids. Actually, the absorption bands related to such surface states lay in the energy scale far below the fundamental absorption threshold, sometimes in visible. Therefore the dispersed wide band gap solids may be rated as a potential competitors for relatively narrow band gap solids. As the example, the absorption band assigned to exciton-like excitation of 3-coordinated oxygen corner sites in $\mathrm{MgO}$ peaks at $4.6 \mathrm{eV},[5,6,10]$ while the bulk exciton band maximum is located at $7.7 \mathrm{eV}$. Similar, the STE in the subsurface (0001) layer in $\alpha$ quartz $\left(E_{g}=11 \mathrm{eV}\right)$ has dropped in energy by $0.7 \mathrm{eV}$ in respect to the energy of bulk exciton $(3.7 \mathrm{eV})$, the further energy drop by $0.5 \mathrm{eV}$ occurs due to reaction of STE with $\mathrm{OH}^{-}$group at the surface with formation of $\mathrm{OH}$ radicals [22]. Note also, that the amount of surface defects may exceed the total amount of intrinsic and extrinsic defects in the bulk of sufficiently small solid particle. So, the surface of small particles may predominantly absorb actinic light in sub band gap region. In addition, roughly, surface low-coordinated (LC) electronic excitations are less mobile ("more localized") than the bulk excitons [5, 6, 10]. Regarding to the ability for moving the above mentioned 3-coordinated (3C) corner exciton can be described as bound or self-trapped exciton, for which only "hopping" is possible. Obviously, even localized surface excitations are accessible for molecules (reagents). So the recombination ("quench- ing") of the surface excitations caused by their interaction with "detrimental" surface defects may be much less effective than that for free bulk excitons and free carriers.

The photoexcitation of surface foreign defects related to surface chemical reactions may be very specific compared with that for bulk defects (see, for example [28]). In a case of phoexcitation of surface defects the transport of carriers from the balk to the surface (path 9-3, Figure 3) may be not needed.

\section{EXPERIMENTAL EVIDENCE FOR PHOTOADSORPTION AND PHOTOCATALYSIS ON WIDE BAND GAP SOLIDS AT SUB BAND GAP PHOTOEXITATION}

It is very likely that, the concept of "photoexcitation at sub band gap region" had been used first in the pioneer studies carried out by J. H. De Boer (Netherlands) and A. N. Terenin (St.-Petersburg University, Russia) in the early 1930s [29, 30]. The photodissociation and photodesorption of small molecules such as $\mathrm{I}_{2}, \mathrm{Br}_{2}, \mathrm{NO}_{2}$ adsorbed at alkali halides, alkali earth fluoride vacuum deposited films, on silica, on alumina and on some other highly dispersed "white" powders have been studied by using VIS spectroscopy method. However the direct absorption of actinic light by molecules adsorbed at the optically inert surface mainly has been considered as the primary photo process in the early works. Note, because the adsorbed molecule can be described as the specific surface defect, formally the case can be refereed as the absorption of Type III or IV (Figure 1). The studies of photodesorption of small molecules and their fragments from the smooth perfect surfaces of wide band gap solids [31] is an example of the later realization of the above mentioned early concept. Along with the evolution of the main stream of the photocatalysis which is based on the well known semiconductor model of photocatalyst it has become evident that the sub band gap photoexcitation (h $v_{2}$, Figure 3 ) of wide band gap solids (dielectrics) also induces the chemical surface reactions. For example, in the early work [32] the absorption of near UV light by absorbed molecules (the system $\mathrm{NH}_{3} / \gamma-\mathrm{Al}_{2} \mathrm{O}_{3}$ ) has been considered as the reason for ammonia photolysis, while the later study [33] has shown that the absorption of light by adsorbent $\left(\mathrm{H}_{2} \mathrm{O} / \gamma-\mathrm{Al}_{2} \mathrm{O}_{3}\right)$ in the same spectral region (the red limit $\mathrm{E}_{\text {red }} \approx 4.0 \mathrm{eV}$ ) causes the adsorbed water photolysis. In the pilot studies of photoadsorption of oxygen, hydrogen and methane on the series of 35 metal oxides $[34,35]$ the empirical correlation between the photoadsoption activities (A) of the oxides sample specimens and the oxide's band gap energy $\left(\mathrm{A} \propto \mathrm{E}_{\mathrm{g}}\right.$ ) has been established, the photoexcitation of the most active oxides only at $h v_{2}$ region (Figure 3 ) has been available. The wide band gap oxides also occurred to be sufficiently 
more active than narrow band gap oxides in respect to the photolysis of adsorbed water [36] (see, also [37]). Similar, in the studies of a series of alkali halides the photoadsorption of $\mathrm{O}_{2}$ and $\mathrm{CO}_{2}$, the photodecomposition of $\mathrm{CO}_{2}$ and $\mathrm{H}_{2} \mathrm{O}$ and the photooxidation of $\mathrm{H}_{2}$ and $\mathrm{CO}$ at repeated irradiation of adsorbents (except of iodides) with oxygen preliminary photoadsorbed have been observed (see [38] and references there). It has been established that the red limits of water and $\mathrm{CO}_{2}$ photolysis are close to $5 \mathrm{eV}$, while the red limits of oxygen photoadsorption are considerably shifted $\left(\mathrm{E}_{\text {red }} \approx\right.$ $3.0 \div 4.0 \mathrm{eV}$ ) to the red compared with the alkali halides bulk exciton absorption bands $(5 \div 10 \mathrm{eV})$. From the correlation between the photoasorption and photocatalytic activities of alkali halides established [39] one may conclude that the actinic light is absorbed by solids for all of above mentioned photostimulated reactions.

The more detailed information about the photoexcitation of solids related to the surface photoreactions may be elucidated from the so called spectral dependencies of photoadsorption quantum yield [1, 35, 40-48].

The main characteristics of the spectral dependencies of the quantum yields for photoadsorption of small molecules are as following: i) the photoadsorption red limits $\left(\mathrm{E}_{\mathrm{red}}\right)$ for both acceptor $\left(\mathrm{O}_{2}\right)$ and donor $\left(\mathrm{H}_{2}, \mathrm{CH}_{4}\right)$ molecules lay far below the fundamental absorption threshold for majority of oxides; ii) the spectral dependencies $\Phi(\mathrm{h} v)$ have structure, the maximal values $\Phi_{\max }(\mathrm{h} v)$ are located within the $\mathrm{E}_{\mathrm{red}}$ and the $\mathrm{E}_{\mathrm{g}}$ interval for some oxides; iii) the $\Phi(\mathrm{h} v)$ curves for donor molecules and for oxygen overlap, for $\mathrm{Sc}_{2} \mathrm{O}_{3}$, $\mathrm{ZrO}_{2}, \mathrm{CeO}_{2}$ the red limits Ered for $\mathrm{H}_{2}, \mathrm{CH}_{4}$ and $\mathrm{O}_{2}$ photoadsorption are the same; iv) in some cases ( $\mathrm{ZnO}$, $\left.\mathrm{TiO}_{2}\right)$ the $\Phi_{\text {max }}$ values exceed 0.1 and even reach unit [35, 41, 43, 45].

For example, Figure 4 shows the $\Phi(\mathrm{h} v)$ dependence for photoadsorption of oxygen, hydrogen and methane on commercial grade powdered $\mathrm{MgO}\left(\mathrm{S}_{\mathrm{BET}}=50 \mathrm{~m}^{2} \mathrm{~g}^{-1}\right)$. The $\Phi(h v)$ dependencies have been obtained using the so called "black-body-reactor" [1, 35].

The theoretical modeling of the spectral dependencies of photoadsorption quantum yield [44] demonstrated that the structure of $\Phi(\mathrm{h} v)$ spectral dependencies for intrinsic and color centers absorption region $\left(h \nu_{2}\right.$ and $h \nu_{3}$ respectively, Figure 3 ) arise mostly from some background "inactive" absorption of light in the sample. The photoadsorption quantum yield has no spectral dependence if the inverse absorption coefficient exceed the particle size $(1 / \alpha \gg d)$, which is the case of dispersed samples using in the photoadsorption studies. The same is true for surface absorption bands. Nevertheless, the inactive background absorption "develops" somehow [43-45] the shape and peak position of active absorption bands. So, one can assign the poorly resolved broad peaks at 3.6-3.8 eV and 4.5-4.7 eV (Figure 4) to the absorption of species re-

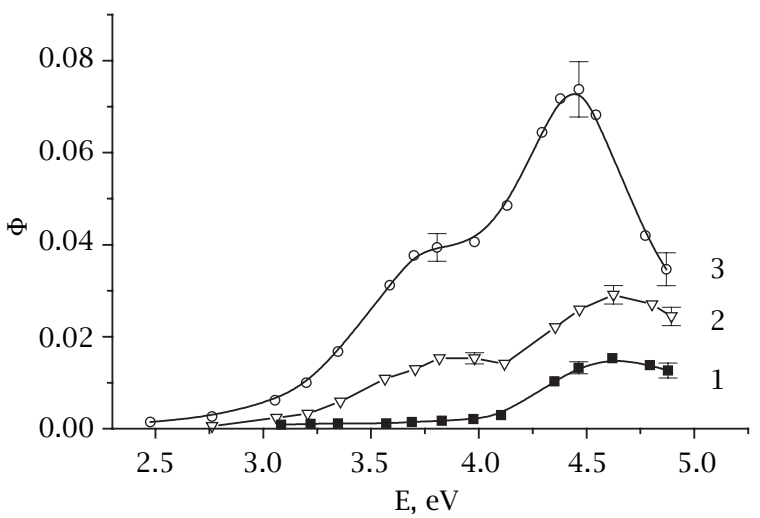

Figure 4. Spectral dependencies of quantum yields of photoadsorption of oxygen (1), hydrogen (2), and methane (3) on powdered MgO [45]. \{Copyright by the American Chemical Society.\}

sponsible for photoadsorption of donor and acceptor molecules on magnesia. The photoadsorption, which is induced in 3.6-3.8 eV band, only for donor molecules has been tentatively attributed to photo liberation of holes from pre-existing V-like centers in the bulk with following trapping at the surface [45]. Note, V centers likely arise due to $\mathrm{MgO}$ high temperature oxygen pretreatment, which was accepted in the studies refereed. In contrast, the band $4.5-4.7 \mathrm{eV}$ in $\Phi(\mathrm{h} v)$ spectra (Figure 4) have been assigned $[45,48]$ to the surface lowcoordinated $3 \mathrm{C}$ exciton-like states in $\mathrm{MgO}$ with optical absorption band centered at $4.6 \mathrm{eV}[5,6,10]$. In general the formation of low-coordinated surface excitation at oxides may be depicted as [48]:

$$
\begin{aligned}
\left(\mathrm{M}^{\mathrm{n}+}-\mathrm{O}^{2-}\right)_{\mathrm{LC}}+\mathrm{h} v & \longrightarrow\left(\mathrm{M}^{(\mathrm{n}-1)+}-\mathrm{O}^{-}\right)^{*}{ }_{\mathrm{LC}} \\
& \longrightarrow\left(\mathrm{O}^{-}\right)_{\mathrm{LC}}+\mathrm{e}_{\mathrm{tr}}
\end{aligned}
$$

i.e., as the formation of LC exciton and its following decay onto self-trapped hole $\left(\mathrm{O}^{-}\right)_{\mathrm{LC}}$ and electron $\mathrm{e}_{\mathrm{tr}}$ captured by appropriate surface trap. (The path 9-4, Figure 3). The surface center with trapped hole is the crucial centers for many photocatalytic reactions (see, for example, [49-52]). Recently a few special features, related to the $\mathrm{LC}$ exciton photocatalysis have been emphasized [10]. The mobility of $4 \mathrm{C}$ excitation at $\mathrm{MgO}$ (001) surface (edges sites) have been predicted and demonstrated in the ESR and FTIR studies of hydrogen photoadsorption $[6,10]$. However, it has been concluded that the chemically inactive $4 \mathrm{C}$ excitons move towards $3 \mathrm{C}$ active sites, the escape of $4 \mathrm{C}$ "edge" exciton $\left(\mathrm{E}_{4 \mathrm{C}}=5.7 \mathrm{eV}\right)$ onto the regular $(001)$ sites $\left(\mathrm{E}_{5 \mathrm{C}}=6.15 \mathrm{eV}\right)$ is difficult. To cover the energy deficit for the separation of electron and hole coupled into $3 \mathrm{C}$ exciton, the absorption of photon by exciton (eq. (18)) (note, the second one in overall) for formation of separated electron and hole surface centers has been suggested. 
The absorption of light by extrinsic surface defects also can result in the formation of a pairs of active centers. For example, the red shift of the spectral limit for photooxidation of $\mathrm{CO}$ over $\mathrm{ZnO}$ has been attained via substitution of $\mathrm{Zn}^{2+}$ surface cations by $\mathrm{Li}^{+}$dopants

$$
\begin{aligned}
\mathrm{ZnO}(\mathrm{Li})_{\mathrm{s}}+\mathrm{h} v_{2} & \longrightarrow\left[\mathrm{O}^{2-}-\mathrm{Li}^{+}\right]_{\mathrm{s}}^{*} \\
& \longrightarrow\left[\mathrm{O}^{-}-\mathrm{Li}^{+}\right]_{\mathrm{s}}+\mathrm{e}_{\mathrm{tr}}
\end{aligned}
$$

At that the active surface hole $\mathrm{O}^{-}{ }_{\mathrm{s}}$ trapped by $\mathrm{Li}^{+}$cation site stays immobile [41] while electron $\left(e_{t r}\right)$ is trapped by proper surface defect. Similar, the vanadium ions supported at silica $\left(\mathrm{V}^{5+} \mathrm{O}^{2-}\right)_{\mathrm{s}}$ absorbs actinic light with formation of active centers $\left(\left[\mathrm{V}^{4+}-\mathrm{O}^{-}\right]^{*}\right)_{\mathrm{s}}$ for oxidative coupling of methane. The latter have been described as charge transfer complexes. Note, the luminescent relaxation of this and some other excited transition metal complexes with millisecond scaled decay time has been observed [53].

It will be emphasized, that the LC excitons, excited transition metal complexes [53] as well as the excited states of other dopant metal ions [41] mentioned above (eq. (19)) can be considered as bound excitons whose decay products are the pairs of chemically active centers. The decay products arise directly at the surface. The formation of separate pairs of active centers at sub band gap irradiation has been considered as the forcible argument for surface character of photoexcitation for wide bang gap solid a long ago [35]. The resemblance between the spectral dependencies of quantum yields for donor molecules and for oxygen below fundamental absorption threshold can be seen for $\mathrm{Sc}_{2} \mathrm{O}_{3}$, $\mathrm{ZnO}, \mathrm{ZrO}_{2}, \mathrm{CaO}$ [45]. In latter case, the $\Phi(\mathrm{h} v)$ curves are quite similar to those outlined above for $\mathrm{MgO}$ and they are shifted into the red in accordance with LC exciton band positions for $\mathrm{CaO}$ [5].

At the same time, the alternative mechanism of both electrons and holes photogeneration based on the so called photoconversion of pre-existing $\mathrm{F}$ centers in wide band oxides has been proposed. The photoconversion for alumina [54] can be presented by

$$
\begin{aligned}
& \left\{\mathrm{F}^{+}--\mathrm{O}^{2-}\right\}+\mathrm{h} v \longrightarrow\left\{\left(\mathrm{F}^{+}\right)^{*}--\mathrm{O}^{2-}\right\} \\
& \longrightarrow\left\{\mathrm{F}+\mathrm{O}^{-}\right\}(=\mathrm{F}+\mathrm{h}) \\
& \mathrm{F}+\mathrm{h} v \longrightarrow \mathrm{F}^{*} \longrightarrow \mathrm{F}^{+}+\mathrm{e}^{-} \\
& \mathrm{F}^{+}+\mathrm{h} v \longrightarrow\left(\mathrm{F}^{+}\right)^{*} \longrightarrow \mathrm{V}_{\mathrm{a}}+\mathrm{e}^{-}
\end{aligned}
$$

Here $\mathrm{F}^{+}$and $\mathrm{F}$ are pre-existing anion vacancies $\left(\mathrm{V}_{\mathrm{a}}\right)$ with one or two trapped electrons respectively, $\mathrm{O}^{2-}$ is the symbol of oxygen anion adjacent to anion vacancy (or the symbol of oxygen sublattice) in the balk of crystal particle, $\mathrm{O}^{-}(=\mathrm{h})$ and $\mathrm{e}^{-}$are free hole and electron delocalyzed in oxygen and metal sublattice of the solid respectively. (Note, the symbols $\left\{\mathrm{F}^{+}-\mathrm{O}^{2-}\right\}$ and $\left\{\left(\mathrm{F}^{+}\right)^{*}-\right.$ $\left.\mathrm{O}^{2-}\right\}$ (eq. (20)) are the same as the symbols $\mathrm{F}^{+}$and $\left(\mathrm{F}^{+}\right)^{*}$ (eq. (21)) respectively.) The free electrons appear due to thermal ionization of photoexcited $\mathrm{F}^{*}$ and $\left(\mathrm{F}^{+}\right)^{*}$ centers (eq. (21)). The "key stage" of the mechanism is the tunneling of valence band electron (the electron delocalized in oxygen sublattice, denoted as $\mathrm{O}^{2-}$, eq. (20)) to unoccupied level of excited $\left(\mathrm{F}^{+}\right)^{*}$ center with formation of $\mathrm{F}$ center (in the ground state) and free hole $\left(\mathrm{O}^{-}=\mathrm{h}\right.$ ) (eq. (20)). The latter is possible since the ground state of $\mathrm{F}^{+}$center is located below the top of valence band in $\mathrm{Al}_{2} \mathrm{O}_{3}$ [54]. Later, the $\Phi(\mathrm{h} \nu)$ dependence for oxygen photoadsorption on $\mathrm{MgO}$ peaked at $\sim 5 \mathrm{eV}$ in strongly overlapped $\mathrm{F}$ and $\mathrm{F}^{+}$centers absorption bands has been reported [42]. The photoadsorption of oxygen on hole centers has been suggested for $\mathrm{Al}_{2} \mathrm{O}_{3}, \mathrm{BeO}$ and $\mathrm{MgO}$, the photoconversion (eqs. (20) and (21)) in $\mathrm{MgO}$ has been taken to trust by analogy with $\mathrm{Al}_{2} \mathrm{O}_{3}$. Regardless to the shortcomings of the above mentioned model for $\mathrm{MgO}$ [42], recently the experimental evidence for free holes formation during the F centers photo conversion in $\mathrm{MgO}$ has been reported [55]. The novel mechanism of $\mathrm{F}$ center conversion in $\mathrm{MgO}$ based on theoretical and experimental studies has been proposed

$$
\mathrm{F}^{+}\left(\mathrm{O}^{2-}\right)+\mathrm{h} v(5 \mathrm{eV}) \rightarrow \mathrm{F}+\mathrm{O}^{-}(\mathrm{h})
$$

In contrast with eq. (20), eq. (22) depicts the transfer of electron to the $\mathrm{F}^{+}$center (the ground states is located at $3 \mathrm{eV}$ above the top of valence band) from the quasi-local state induced by the charge defect in the valence band. As the result free holes appear. The quasi-local state which is located at $2.0 \mathrm{eV}$ below the top of the valence band in $\mathrm{MgO}$ has been theoretically predicted [55]. Note, for both above mentioned mechanisms the $\mathrm{F}\left(\mathrm{F}^{+}\right)$intrinsic defect looks like renewable "self-sensitizing" agent for electrons and holes photo generation via two step absorption of photons below the fundamental threshold of wide band gap solid.

\section{EXCITON INDUCED SURFACE REACTIONS OF SMALL MOLECULES}

The specific of exciton induced surface chemical transformation will be illustrated below by a few examples. The $\gamma$-radiolysis of adsorbed water for the series of 30 metal oxides has been studied [56]. (Note, the fast relaxation of energy and momentum of gamma- and $\mathrm{X}$ rays induced "hot" carriers in the solids results in the formation of free carriers near the bottom and the top of conduction and valence bands respectively, transport properties of the excitons originating from the subsequent electron-hole coupling are quite similar to those for excitons induced by UV-light.) The dependence of effective hydrogen yield on the oxide band gap energy $\left(E_{g}\right)$ has shown sharp "resonant-like" maximum at $\sim 5 \mathrm{eV}$ which corresponds to the energy of $\mathrm{H}-\mathrm{OH}$ bond $(5.1 \mathrm{eV})$ of $\mathrm{H}_{2} \mathrm{O}$ molecule. It has been concluded that the resonant coupling of bulk excitons with adsorbed water molecules are responsible for water 
decomposition. The exciton diffusion length for $\mathrm{ZrO}_{2}$ has been estimated by $\sim 5 \mathrm{~nm}$ [56]. Note, the decomposition of adsorbed water via the resonant triplet-totriplet energy transfer to its dissociative ${ }^{3} \mathrm{~A}_{2}$ state from $\mathrm{T}_{2}$ excited states of naphthalene, diphenyl and some other aromatic molecules deposited on silica has been demonstrated [57]. Tentatively estimated red limits of adsorbed water photolysis for oxides [36] and alkali halides reported [58] are very close to $5 \mathrm{eV}$ regardless to the nature of the adsorbent. The energy transfer from excited surface states to adsorbed water has been proposed in early works [36]. If the latter is the case, adsorbed water molecule seems to be able to "choose itself" the appropriate excited state from the wide variety of exciton-like states which exist in the dispersed wide band gap solids.

The surface reactions observed in alkali halides under irradiation in the bulk exciton absorption bands ( $h v_{1}$, Figure 3 ) are in many respects similar to those photostimulated below the exciton band ( $\mathrm{h} \nu_{2}$, Figure 3 ) [38, 39, 58-60]. For distinctness, KBr will be discussed below. The first exciton band of $\mathrm{KBr}$ (Figure 2) is centered at $186 \mathrm{~nm}$ at $300 \mathrm{~K}$. Photoadsorption of only acceptor molecules $\left(\mathrm{O}_{2}, \mathrm{CO}_{2}, \mathrm{Br}_{2}\right)$, photodecoposition of $\mathrm{H}_{2} \mathrm{O}$ and $\mathrm{CO}_{2}$ have been observed for each spectral region. However, the photooxidation of $\mathrm{H}_{2}$ and $\mathrm{CO}$ have not been detected neither in exciton region $\left(\mathrm{h} v_{1}\right)$ no under combined $\left(\mathrm{h} v_{1}+\mathrm{h} v_{2}\right)$ irradiation. The photoxidation of $\mathrm{H}_{2}$ and $\mathrm{CO}$ for alkali halides are the two-step photoreaction:

$$
\begin{aligned}
& \mathrm{O}_{2} \text { (gas) }+\mathrm{h} \nu_{2} \rightarrow \mathrm{O}_{2} \text { (ads) } \\
& \left.\mathrm{O}_{2}(\text { ads })+\mathrm{h} v_{2} \rightarrow \mathrm{O}_{2} \text { (ads) }\right)^{*}+\mathrm{H}_{2} \text { (gas) } \\
& \text { or } \mathrm{CO}(\text { gas }) \rightarrow \text { products }
\end{aligned}
$$

Here $\mathrm{O}_{2}$ (ads) is tentatively refereed as $\mathrm{O}_{2}{ }^{-}$species among others not identified, $\mathrm{O}_{2}(\mathrm{ads}) *$ is likely $\mathrm{O}_{2}\left({ }^{1} \Delta_{2}\right)$ adsorbed singlet oxygen. The $\mathrm{CO}_{2}$ evolves into the gas in a course of the reaction, while the products of hydrogen oxidation remain at the surface. Each oxygen adsorbed species can be transformed into the reaction products in accordance with stoichiometric ratio for complete oxidation of $\mathrm{CO}$ and $\mathrm{H}_{2}$. The most active electronically excited $\mathrm{O}_{2}\left({ }^{1} \Delta_{2}\right)$ species decay with $\mathrm{k} \leq$ $70 \mathrm{c}^{-1} \mathrm{~s}$ apparent rate constant in vacuum and undergoes the Stern-Volmer quenching by oxygen from a gas. The ratio between the quenching constant and the reaction constant is around 10. The same mechanism of hydrogen photooxidation by oxygen photoadsorbed on alkali halides and alkali earth halides have been discussed elsewhere [61]. In contrast with the preceding, the photoadsorbed oxygen species arising at the surface at irradiation of $\mathrm{KBr}$ in exciton band are not active in respect to photooxidation of $\mathrm{H}_{2}$ and $\mathrm{CO}$ (eqs. (23a) and (23b)). The upper limit for so called photoadsorption capacity, i.e., the ultimate per square centimeter number of molecules that can be photoadsorbed on uniformly irradiated surface has been estimated by $\sim 10^{15} \mathrm{~cm}^{-2}$ for $\mathrm{KBr}[15]$. The latter indicates that the prolong $\left(\sim 10^{4} \mathrm{~s}, 100 \mathrm{~W}\right.$ resonant hydrogen or mercury lamp) irradiation of $\mathrm{KBr}$ in oxygen causes chemical transformation of the sample with formation of new surface phase similar to that for radiation induced chemical transformation of alkali halides [61]. Note, the decay of excitons onto Frenkel pairs (eqs. (13) and (14)) and following reactions do occur in $\mathrm{KBr}$ and alkali iodides under the excitation in exciton band. However the above mentioned respectively slow reactions can be neglected for initial stages of $\mathrm{KBr}$ irradiation. The absence of photooxidation reactions (eqs. (23a) and (23b)) in a case of combined irradiation $\left(\mathrm{h} \nu_{1}+\mathrm{h} v_{2}\right)$ of $\mathrm{KBr}$ with oxygen photoadsorbed at $\left(\mathrm{h} \nu_{2}\right)$ region has been attributed to the photodesorption of the most active oxygen species

$$
\mathrm{O}_{2}{ }^{-} \text {(ads) }+\mathrm{h} \nu_{1} \longrightarrow \mathrm{O}_{2}{ }^{-} \text {(ads) }+\mathrm{e}^{0} \longrightarrow \mathrm{e}+\mathrm{O}_{2} \text { (gas) }
$$

which resembles the reaction (eq. (16)). The apparent photodesorption cross section for the most active oxygen photoadsorbed species has been estimated by $\sim 10^{-15} \mathrm{~cm}^{2}$ at $300 \mathrm{~K}$. So, one can assume that the efficiency of exciton transport to the surface from the near surface area of $\sim 10^{-7}-10^{-6} \mathrm{~cm}$ in depth for $\mathrm{KBr}$ is rather high. No photodesorption of $\mathrm{O}_{2}$ has been observed at $\mathrm{T}<180 \mathrm{~K}$. Photodesorption rate decreases with decreasing temperature by exponential law, the activation energy has been estimated by $(0.4 \pm 0.1) \mathrm{eV}$. The temperature range of $\mathrm{O}_{2}$ photodesorption coincides with the temperature range $\left(\mathrm{T}_{\mathrm{d}}>175 \mathrm{~K}\right)$ of delocalization of self trapped excitons for $\mathrm{KBr}$ [62]. However, selftrapped holes become mobile in $\mathrm{KBr}$ in the same temperature range. So, the desorption of some part of oxygen $\mathrm{O}_{2}{ }^{-}$species via recombination with holes originating from the exciton dissociation are also possible.

\section{PHOTOEXCITATION OF UV-INDUCED COLOR CENTERS RELATED TO PHOTOADSORPTION}

The alkali halides occurred to be convenient adsorbents for demonstration and for studies [15, 38, 39] of the so called photostimulated postsorption (PSPS) of small molecules ( $\mathrm{h} v_{3}$ region, path 1-2-10-3-4-5, Figure 3 ). The exciton decay onto Frenkel defects in alkali halides (eqs. (13) and (14)) as well as interaction of excitons with pre-existing defects (eq. (17)) lead to formation of longlived F centers (here: anion vacancy with trapped electron) and some complex halogen-containing $\mathrm{V}$ centers both in the bulk (Figure 3, path 1-2) and at surface of adsorbent (not shown at Figure 3, the corresponding path is equal to 1-3-4). In a case of alkali halides only the surface centers with trapped electrons are active in respect to adsorption of acceptor molecules. The adsorption of $\mathrm{O}_{2}$ and $\mathrm{CO}_{2}$ in the dark on such centers created by vacuum pre-irradiation of alkali halides in 
$\mathrm{h} v_{1}$ (and $\mathrm{h} v_{2}$ ) spectral region (Figure 3, path 1-3-4, is the example of so called memory or post-sorption effect of Solonitzyn type [63]. However, the considerable number of surface electron traps (S, Figure 3) typically remains empty in a coarse of irradiation of a sample in vacuum due to reverse reactions, similar to reactions (eq. (5)). Therefore the repeated photoexcitation of UVcolored alkali halides in F-center bands (eq. (10)) causes the additional photoadsorption (PSPS) of $\mathrm{O}_{2}$ and $\mathrm{CO}_{2}$ on alkali halides (Figure 3, path 10-3-4-5). Typically the red limit of PSPS is considerably shifted in the red when compared with that for non-irradiated adsorbents. For example, the red limit $\mathrm{E}_{\text {red }}\left(\mathrm{h} \nu_{3}\right) \approx 1.45 \mathrm{eV}$ for PSPS $\mathrm{O}_{2}$ on colored $\mathrm{KBr}$ corresponds to long wave tail of $\mathrm{F}$ absorption band (Figure 2). Quantum yield of PSPS of oxygen has no spectral dependence $(\Phi(h v)=(0.02 \pm 0.002)$ $=$ const) within the F-band of $\mathrm{F}$ center in the agreement with the model developed [44]. The PSPS $\mathrm{O}_{2}$ rate increases with increasing temperature by exponential law. Activation energy estimate $E_{\mathrm{a}}=(0.135 \pm 0.01) \mathrm{eV}$ is in a good agreement with the energy gap between the relaxed $2 p$-state of F-center and the bottom of the conduction band in $\mathrm{KBr}$. In contrast with the rates of PSPS $\mathrm{O}_{2}$ induced in the $\mathrm{F}$ band of $\mathrm{F}$ center, those for $\mathrm{L}$ bands only slightly depend on temperature $[15,38]$. The PSPS of acceptor molecules have been also observed on KI, $\mathrm{RbI}[38,58]$ and on X-rays irradiated $\mathrm{CaF}_{2}$ and $\mathrm{BaF}_{2}$ [64]. The thermally stimulated post-sorption (TSPS) of small molecules on oxides and alkali halides have been discussed elsewhere [13, 38, 45].

PSPS of oxygen for wide band gap oxides is induced at repeated irradiation in F-type color centers band, while PSPS of donor molecules occur under photoexcitation of colored oxides in $\mathrm{V}$ bands. The PSPS of small donor $\left(\mathrm{H}_{2}, \mathrm{CO}, \mathrm{CH}_{4}\right)$ and acceptor $\left(\mathrm{O}_{2}\right)$ molecules have been observed for a wide variety of metal oxides: $\mathrm{La}_{2} \mathrm{O}_{3}$, $\mathrm{Sm}_{2} \mathrm{O}_{3}, \mathrm{Yb}_{2} \mathrm{O}_{3}, \mathrm{Cd}_{2} \mathrm{O}_{3}, \mathrm{HfO}_{2}, \mathrm{ZrO}_{2}$, and for $\mathrm{ZrO}_{2}$ stabilized in the cubic modification with $\mathrm{Y}_{2} \mathrm{O}_{3}$ [13, 45], for $\mathrm{MgAl}_{2} \mathrm{O}_{4}$ [65], $\mathrm{Y}_{2} \mathrm{O}_{3}, \mathrm{Sc}_{2} \mathrm{O}_{3}$ [66]. Note, in the pilot studies [13] with primary excitation of oxides by mercury lamp at $\mathrm{E}\left(\mathrm{h} v_{1}\right) \leq 6.0 \mathrm{eV}$ and with repeated irradiation in visible $\left(\mathrm{E}\left(\mathrm{h} v_{3}\right) \leq 3.1 \mathrm{eV}\right.$ or $\left.2.5 \mathrm{eV}\right)$, the PSPS of oxygen accepted as the test gas has not been detected: i) for relatively narrow band gap poorly photocolored oxides $\left(\mathrm{ZnO}, \mathrm{TiO}_{2}, \mathrm{In}_{2} \mathrm{O}_{3}\right)$, ii) for oxides with $\mathrm{E}_{\mathrm{g}}>6.0 \mathrm{eV}\left(\mathrm{Al}_{2} \mathrm{O}_{3}\right.$, $\mathrm{BeO}, \mathrm{MgO}$ ) and iii) for oxides without F-type color center bands in spectral region $\mathrm{E}(\mathrm{h} v) \leq 3.0 \mathrm{eV}$ such as $\mathrm{Y}_{2} \mathrm{O}_{3}$ and $\mathrm{Sc}_{2} \mathrm{O}_{3}$. For the latter ones PSPS of both donor and acceptor molecules has been observed in the following more detailed studies. Note, the photoexitation of wide band gap solids below $E_{g}$ also can shift the red spectral limits of surface reactions due to photo recharging or photoconversion of pre-existing defects. To author's knowledge firstly the effect of this kind have been detected by photostimulated exchange of labeled oxygen on BeO [67]. So, on line with photo coloration and photo bleaching of color one can consider the PSPS of molecules as characteristic feature of wide band gap photoadsorbents and photocatalysts.

\section{THE EFFICIENCIES AND INTERCONNECTIONS OF DIFFERENT PHOTOEXCITATION PATHWAYS}

The following data (Table 1) show the efficiency of some pathways of $\mathrm{ZrO}_{2}$ photoexcitation, expressed by quantum yields of corresponding product formation (color centers, photoadsorpbed species) or destruction of color centers. The data have been obtained for monoclinic $\mathrm{ZrO}_{2}$ of commercial grade ("os.ch" 7-4, IREA, Russia), $\mathrm{S}_{\mathrm{BET}}\left(\mathrm{N}_{2}\right)=7 \mathrm{~m}^{2} \mathrm{~g}^{-1}$.

The quantum yields for photoadsorption and PSPS have been measured at sufficiently high gas pressure, so they are equal to the quantum yields of formation of corresponding centers. Among the color centers with trapped electrons (denoted as F, Figure 3) the $\mathrm{Zr}^{3+}, \mathrm{F}^{+}$ and $\mathrm{F}$ centers for $\mathrm{ZrO}_{2}$ have been identified by diffuse reflectance spectroscopy and assigned in accordance with the work [71]. V centers have been identified by ESR technique [72]. The method of measurement of the number of UV induce color centers for $\mathrm{ZrO}_{2}$ has been described in details elsewhere [68].

The values of quantum yields for different processes in near surface area of $\mathrm{ZrO}_{2}$ (Table 1) are comparable with each other in order of magnitude. The latter, in particular, manifests itself as effect of photoadsorption on photo coloration and photo bleaching of color established for a large number of wide band gap oxides $[13,68,70]$.

The processes of photoexcitation related to photoadsorption and photocatalysis depicted at the Scheme (Figure 3) seems to be general for wide band gap solids. The formation of color centers in the bulk of wide band gap solids shifts the red limits of photoadsorption or surface photo reactions. The latter looks like sensitization of photocatalyst to visible light. However, color centers are consumed (bleached) in a coarse of photoreaction, the stationary concentration of "sensitizing agent" depends on the intensity of primary UV irradiation. At the same time the interdependence of different photoexcitation pathways can manifest itself as so called spectral selectivity of photocatalyst [15]. For example, the photolysis of $\mathrm{CO}_{2}$ over $\mathrm{KBr}$ under the irradiation both in the spectral regions $\mathrm{h} v_{1}$, (exciton band) and $\mathrm{h} \nu_{2}$ (extrinsic absorption) has been described as dissociative photoadsorption of carbon dioxide with formation of adsorbed oxygen species and evolving of $\mathrm{CO}$ into the gas phase. The reverse reaction of CO photooxidation (eq. (23)) also takes place in a case of photoexcitation of $\mathrm{KBr}$ in the spectral region $\mathrm{h} v_{2}$, and process reaches the equilibrium. The equilibrium can be shifted towards photooxidation by adding photoadsorbed oxygen or by $\mathrm{CO}_{2}$ removal from the gas phase as if it is thermal chemical equilibrium, 
Table 1. Quantum yields of photoadsorption of $\mathrm{O}_{2}$ and $\mathrm{H}_{2}$, and quantum yields of photocoloration and photobleaching for $\mathrm{ZrO}_{2}$.

\begin{tabular}{|c|c|c|c|c|}
\hline Process & $\begin{array}{l}\text { Spectral region, } \\
\mathrm{E}(\mathrm{h} v), \mathrm{eV}\end{array}$ & $\begin{array}{l}\text { Quantum } \\
\text { yield, } \Phi\end{array}$ & Ref. & Path (Figure 3) \\
\hline \multirow{2}{*}{$\begin{array}{l}\text { Photoadsorption } \\
\text { of oxygen }\end{array}$} & $\begin{array}{l}\text { Fundamental absorption } \\
\text { edge }\left(\mathrm{h} v_{1}\right) \\
\mathrm{h} \nu_{1}=4.88 \mathrm{eV}\end{array}$ & $\begin{array}{l}0.02 \pm 0.003 \\
0.045 \pm 0.003\end{array}$ & $\begin{array}{l}{[68]^{*}} \\
{[45]^{*}}\end{array}$ & $1-3-4-5$ \\
\hline & $\begin{array}{l}\text { Extrinsic bulk or/and } \\
\text { surface absorption }\left(\mathrm{h} v_{2}\right) \\
\mathrm{h} v_{2}=3.40 \mathrm{eV}\end{array}$ & $0.02 \pm 0.003$ & {$[45]$} & $\begin{array}{l}8-3-4-5 \\
\text { or/and } \\
9-4-5\end{array}$ \\
\hline PSPS of oxygen & $\begin{array}{l}\text { Overlapping } \mathrm{F}^{+} \text {and } \mathrm{V} \\
\mathrm{UV} \text { induced color } \\
\text { centers bands }\left(\mathrm{h} \nu_{3}\right) \\
\mathrm{h} \nu_{3}=2.84 \mathrm{eV}\end{array}$ & $0.16 \pm 0.02$ & {$[70]$} & $10-3-4-5$ \\
\hline \multirow{2}{*}{$\begin{array}{l}\text { Photoadsorption of } \\
\text { hydrogen }\end{array}$} & $\begin{array}{l}\text { Fundamental absorption } \\
\text { edge }\left(\mathrm{h} v_{1}\right) \\
\mathrm{h} v_{1}=4.88 \mathrm{eV}\end{array}$ & $0.025 \pm 0.003$ & {$[45]$} & $1-3-4-5$ \\
\hline & $\begin{array}{l}\text { Extrinsic bulk or/and } \\
\text { surface absorption }\left(\mathrm{h} v_{2}\right) \\
\mathrm{h} v_{2}=3.40 \mathrm{eV}\end{array}$ & $0.01 \pm 0.001$ & {$[45]$} & $\begin{array}{l}8-3-4-5 \\
\text { or/and } \\
9-4-5\end{array}$ \\
\hline PSPS of hydrogen & $\begin{array}{l}\text { Overlapping } \mathrm{F}^{+} \text {and } \mathrm{V} \\
\mathrm{UV} \text { induced color } \\
\text { centers bands }\left(\mathrm{h} \nu_{3}\right) \\
\mathrm{h} \nu_{3}=2.84 \mathrm{eV}\end{array}$ & $0.057 \pm 0.007$ & {$[70]$} & $10-3-4-5$ \\
\hline $\begin{array}{l}\text { Photocoloration } \\
\text { (in vacuo) }\end{array}$ & $\begin{array}{l}\text { Fundamental absorption } \\
\text { edge }\left(\mathrm{h} v_{1}\right) \\
\mathrm{h} v_{1}=4.88 \mathrm{eV}\end{array}$ & $0.13 \pm 0.03$ & [68] & $1-2$ \\
\hline $\begin{array}{l}\text { Photobleaching of } \\
\text { color centers } \\
\text { (in vacuo) }\end{array}$ & $\begin{array}{l}\text { Overlapping } \mathrm{F}^{+} \text {and } \mathrm{V} \\
\mathrm{UV} \text { induced color } \\
\text { centers bands }\left(\mathrm{h} v_{3}\right) \\
\mathrm{h} \nu_{3}=2.84 \mathrm{eV}\end{array}$ & $0.32 \pm 0.03$ & {$[70]$} & $\begin{array}{l}10-1^{\prime} \\
\text { (see also } \\
\text { eqs. ( } 7) \text { and (9)) }\end{array}$ \\
\hline
\end{tabular}

${ }^{*}$ The discrepancy between $\Phi$ values for oxygen photoadsorption is likely caused by the difference in the sample pre-treatment procedure [69], accepted in the works [45] and [68].

which follows the Le Chatellier principle. In contrast to preceding, oxygen photodesorption caused by excitons ( $h v_{1}$, eq. (24)) removes the active oxygen species from the surface and the reaction of $\mathrm{CO}_{2}$ looks like "nonsaturated" as in the case of oxygen photoadsorption. Thus, the ratio of active and inactive oxygen species on the surface depends on the wavelength of actinic light, and so does the selectivity of alkali halides catalysts towards either $\mathrm{CO}$ photooxidation or $\mathrm{CO}_{2}$ photolysis. The similar spectral selectivity of $\mathrm{TiO}_{2}$ has been firstly reported [50]. In the case of methane conversion to ethane, ethylene and other hydrocarbons over $\mathrm{TiO}_{2}$, the significantly higher chemical yield of hydrocarbons formation was observed on titania illumination in the extrinsic absorption region ( $\left.\mathrm{h} v_{2}\right)$ compared to that obtained under illumination in the fundamental absorption band $\left(\mathrm{h} v_{1}\right)$, where the products of complete oxidation of methane dominate. Recently the spectral selectivity of photocatalyzed reactions of phenol on the surface of $\mathrm{TiO}_{2}$ nanoparticles has been reported [47].

\section{PHOTOADSORPTION (PHOTOCATALYTIC) CENTERS. LIFETIME OF ACTIVE STATES}

By definition the photoadsorption center is "a surface site or a surface defect in its active state after photoexcitation capable of forming photoadsorbed species by a chemical interaction with adsorbate molecules (or atoms, or ions)." In turn, the active state of a surface photoadsorption center is "an electronically excited surface center, or a surface center (surface site) with a trapped photogenerated charge carrier, that interacts with atoms, molecules or ions at the solid/liquid, liquid/liquid, solid/gas, or solid/liquid interfaces with formation of chemisorbed species" [1]. The similar definition has been suggested for photocatalytic center.

For example, in accordance with the definition the well known $\mathrm{O}_{\mathrm{s}}{ }^{-}$center is the active state of some surface hole trap considering as the photoadsorption (photocatalytic) center. Among such hole traps are the surface cation vacancy or substitutional $\mathrm{Li}^{+}$ion at the 
surface of ZnO [41]. Similar, one should consider the 3-coordinated $\mathrm{O}^{-}{ }_{3 \mathrm{C}}$ hole [10] (see above) as the active state of photoadsorption center which is the oxygen $\left(\mathrm{O}^{2-}{ }_{3 \mathrm{C}}\right)$ corner site for $\mathrm{MgO}$. Indeed, the $3 \mathrm{C}$ oxygen is the pre-existing intrinsic defect (denoted as S, Figure 3), its transition to the active state occurs via photoexcitation. The latter includes the absorption of photon with formation of $3 \mathrm{C}$ exciton and following exciton decay onto self-trapped hole $\left(\mathrm{O}^{-}{ }_{3 \mathrm{C}}\right)$ and electron.

The distinguishing of two states of photoadsorption (photocatalytic) center is reasonable in order to describe a large number of distinctive features of photoadsorption and photocatalysis. In contrast with adsorption and catalysis, the active (in respect to chemical interaction) state of photoadsorption (photocatalytic) center always decays by some physical pathway with formation of inactive "ground" state of the center. The latter is identified as "photoadsorption (photocatalytic) center" [1]. The existence of the physical decay (relaxation) of active state of such centers allows to apply the notion of "lifetime" in respect to the active state of photoadsorption (photocatalytic) center.

The lifetime of active center and LH kinetics. To author's knowledge, firstly the notion "lifetime" in respect to photoadsorption center has been used in the studies of hydrogen photoadsorption on $\mathrm{TiO}_{2}$ a long ago [73]. In order to describe the experimental dependence of the initial (quasi-stationary) photoadsorption rate on hydrogen pressure, which is fitted by LangmuirHinshelwood type curve, the simple mechanism has been proposed

$$
\begin{array}{rlrl}
\mathrm{S}+\mathrm{h} v & \longrightarrow \mathrm{S}^{*} & & k_{\mathrm{abs}} \\
\mathrm{S}^{*} & \longrightarrow \mathrm{S} & k_{d} \\
\mathrm{~S}^{*}+\mathrm{M}(\text { gas }) & \longrightarrow \mathrm{M}(\text { ads }) & k_{\mathrm{a}}
\end{array}
$$

Here (in the terms suggested [1]) $\mathrm{S}$ is the photoadsorption centers ("potencial photadsorption center" [35, 73]), $\mathrm{S}^{*}$ is active state of photoadsorption center ("photoadsorption center" [35, 73]), M(ads) is photoadsorbed species, which corresponds to $\mathrm{M}^{+}$or $\mathrm{M}^{-}$ species depicted at Figure 3. Equation (25) describes the photoexcitation of adsorbent with formation of active $\mathrm{S}^{*}$ centers. Equation (27) depicts the adsorption of molecule M(gas) or "chemical decay" of the active states $S^{*}$, while eq. (26) displays the "physical decay" of $\mathrm{S}^{*}$ states with the first-order constant $\mathrm{k}_{\mathrm{d}}$. The following expression corresponds to the mechanism (eq. (25)-(26))

$$
r_{0}=-\left.\frac{d p}{d t}\right|_{t=0}=k_{\mathrm{abs}} I S_{0} \frac{k_{a} p}{k_{d}+k_{a} p}
$$

where $r_{0}$ is the initial (quasi-stationary) photoadsorption rate, $S_{0}$ is the initial concentration of photoadsorption centers, $p$ is gas pressure and $I$ is the photon flux, i.e., the number of incident photons per unit area, per unit time. [1, 35]. The second-order constant $k_{\mathrm{a}}$ corresponds to the chemical step of photoadsorption, while the rate constant for photoexcitation (eq. (25)) can be described as absorption cross section $\left(k_{\mathrm{abs}}=\sigma\right)$ related to the photoabsorption center S. The ratio $k_{\mathrm{a}} / k_{\mathrm{d}}$ can be evaluated from the experimental dependence $r_{0}(p)$. In this way the low limit of lifetime $\tau=1 / \mathrm{k}_{\mathrm{d}}$ for photoadsorption centers for $\mathrm{H}_{2} / \mathrm{TiO}_{2}$ system has been estimated by $\sim 10^{-2} \mathrm{~s}$ [73]. The lifetime of photoadsorption centers for a lot of systems gas/wide band gap solid have been estimated by $10^{-3}-10^{-1} \mathrm{~s}$ using LH type kinetics obtained for pressure range $0.1-10 \mathrm{~Pa}$ (see, for example [15, 35]).

Obviously, the mechanism (eqs. (25)-(27)) is similar to that for some simplest photochemical reaction. It also reminds the simplest Stern-Volmer mechanism for luminescence ( $\mathrm{S}^{*} \rightarrow \mathrm{S}+\mathrm{h} v_{\text {lum }}$, see eq. (26)) with quenching (eq. (27)). At the same time one may confuse reading eq. (28) as the well known Langmuir-Hinshelwood kinetics

$$
r_{0}=-\left.\frac{d p}{d t}\right|_{t=0}=k(I) \frac{K p}{1+K p}
$$

where $k(I)$ is the apparent rate constant, $K=k_{\mathrm{a}} / k_{\mathrm{d}}=$ $k_{\mathrm{a}} \tau$ is the Langmuir equilibrium constant, where, in turn, $k_{\mathrm{a}}$ is the second order adsorption constant, while the inverse desorption constant $\tau=1 / \mathrm{k}_{\mathrm{d}}$ means the "residence time" for adsorbed molecules.

The lifetime $\tau=1 / k_{\mathrm{d}}$ (eq. (26)) can be considered as the true inverse first-order constant for only a few types of active state of photoadsorption center. For example, it could be electronically excited surface center or the self-trapped surface exciton. The formation of the photoadsorption center whose active state arises via photo carrier trapping (for distinctness, via electron trapping) can be expressed as

$$
\mathrm{S}+\mathrm{e} \rightarrow \mathrm{S}^{-} \quad\left(\text { carrier trapping, } \mathrm{k}_{\mathrm{tr}}\right)
$$

where $\mathrm{k}_{\mathrm{tr}}$ is the bimolecular constant for photo carrier trapping by photoadsorption center $\mathrm{S}$. The following decay pathways for active state of the photoadsorption center exist

$$
\begin{aligned}
& \mathrm{S}^{-} \longrightarrow \mathrm{S}+\mathrm{e} \quad\left(\text { thermal ionization, } \mathrm{k}_{\mathrm{th}}\right) \\
& \mathrm{S}^{-}+\mathrm{h} v \longrightarrow \mathrm{S}+\mathrm{e} \quad(\text { photo ionization, } \sigma) \\
& \mathrm{S}^{-}+\mathrm{h} \longrightarrow \mathrm{S} \quad(\text { recombination with carrier } \\
& \left.\quad \text { of opposite sign, } \mathrm{k}_{\mathrm{r}}\right)
\end{aligned}
$$

For only the photoadsorption center of shallow trap type (eq. (31)) at constant ambient temperature the true first order decay can be expected. For the deep traps the apparent decay constants are presented as $\mathrm{k}_{\mathrm{d}}=\sigma \mathrm{I}$ (eq. (32)), and as $\mathrm{k}_{\mathrm{d}}=\mathrm{k}_{\mathrm{r}}$ [h] (eq. (33)). In the latter case [h] is the concentration of photo holes or, in general case, is the concentration of carriers of opposite sign 
in respect to trapped ones (eq. (33)). (We do not consider here the tunneling decay of active centers, which is also possible [74]). Note, the concentration of photo carriers depends on light intensity, and so both decay constants for deep photoadsorption center depend on photon flux. The latter approach has been used to describe the interdependence of photoadsorption rate on pressure and on light intensity observed in the studies of the $\mathrm{O}_{2} / \mathrm{ZrO}_{2}$ system [75]. The following generalization of eq. (28) has been obtained for a case of linear dependence of free carriers concentration on light intensity

$$
r_{0}(p, I)=-\left.\frac{d p}{d t}\right|_{t=0}=\frac{a I p}{b I+c p}
$$

where $a, b, c$ are constants which depend neither on photon flux $I$ no on gas pressure $p$. Note, eq. (34) at $I=$ const can be brought to conformity with commonly accepted LH kinetics (eq. (29)) with hidden parameter $\tau=1 / k_{\mathrm{d}}$. Commonly accepted LH kinetics (eq. (29)) and alternative Eley-Rideal-like kinetics, which is under consideration, can superimpose at relatively low gas pressure and high coverage of the surface by adsorbate. In this case the diffusion of adsorbed molecules to photadsorption centers (11, Figure 3) can be considered (For further discussion, see: [76, 77]). Note also, that the sublinear dependence of the reaction rate on light intensity is described by eq. (34) at condition: $b I \geq c p$. The latter can be satisfied at moderate or weak photon flux depending on the gas pressure. At that the quantum yield of the reaction increases with light intensity decreasing and no longer depends on pressure [76]. (For further discussion of low intensity photocatalysis, see also, [78, 79]).

Solonitzyn's effect. Post-sorption or memory effect of Solonitzyn type [1], i.e., the adsorption in the dark caused by the pre-irradiation of solid surface has been recognized firstly a long ago [63]. In the following studies the post-sorption of small molecules has been observed on a large number of wide band gap solids $[35,80]$. In order to characterize the memory effect the so called post-sorption coefficient $\eta$ has been suggested [35]

$$
\eta(t)=\frac{N_{\mathrm{ps}}(t)}{N_{\mathrm{ph}}(t)}
$$

where $N_{\mathrm{ps}}(t)$ is the number of post-sorbed molecules and $N_{\mathrm{ph}}(t)$ is the number of photoadsorbed molecules for the same pre-irradiation and irradiation time $t$. Typically, the dependence of $\eta$ from delay time between the termination of pre-irradiation and contact of a sample surface with a gas is marked feebly for wide band gap photoadsorbents [80]. The constancy of $\eta$ at the delay time up to $10^{5} \mathrm{~s}$ has been verified by measurement for the $\mathrm{O}_{2} / \mathrm{ZnO}$ system [35]. The post-sorption coefficients $\eta$ obtained at sufficiently high exposition $\left(t \sim 10^{2}-\right.$ $10^{3} \mathrm{~s}, \sim 100 \mathrm{~W}$ mercury lamps), typically, have ranged

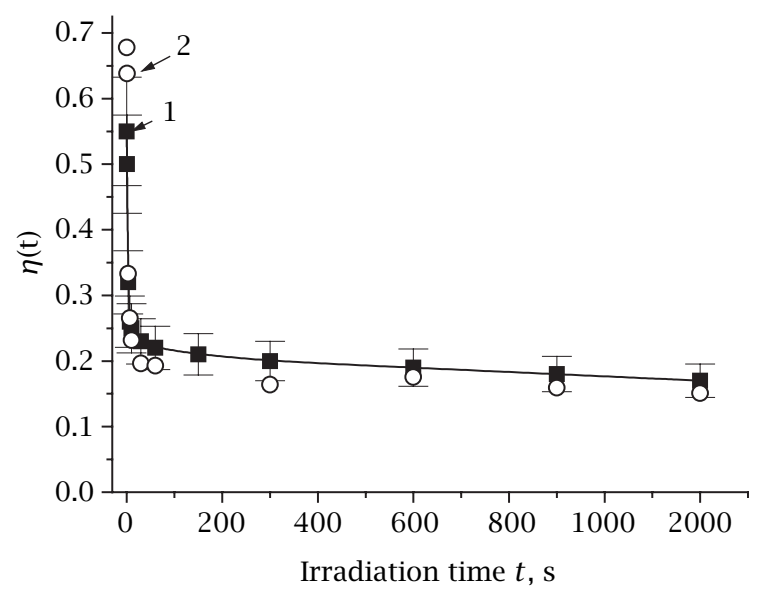

Figure 5. Dependence of post-sorption coefficient of oxygen on irradiation (pre-irradiation) time for powdered $\mathrm{ZrO}_{2}$. The delay time of $600 \mathrm{~s}$ has been accepted, the manometric (curve 1) and thermally programmed desorption methods (curve 2) have been applied to determine the number of photoadsorbed and post-sorbed molecules.

from $10^{-1}$ to $10^{-2}$ for wide band gap oxides. The latter had been described as a fraction of "long-lived" photoadsorption centers in respect to the total number of photoadsorption centers. The most part of the centers had been assigned to some photoadsorption centers of shallow trap type, whose lifetime $\tau$ could be estimated by means of ER-like kinetics (eq. (28)).

However, the lifetime of deep photoadsorption centers picked up under illumination of solids increases drastically along with the termination of irradiation. The electroneutrality condition for wide band gap solid under illumination in vacuum can be expressed by

$$
\mathrm{e}+\mathrm{S}^{-}(\mathrm{vac})+\mathrm{F}(\mathrm{vac})=\mathrm{h}+\mathrm{S}^{+}(\mathrm{vac})+\mathrm{V}(\mathrm{vac})
$$

where, typically, the concentration of free photo carriers becomes much lower than the concentration of trapped ones rapidly along with the beginning of irradiation: $[\mathrm{e}, \mathrm{h}] \ll\left[\mathrm{S}^{-}, \mathrm{F}, \mathrm{S}^{+} \mathrm{V}\right]$ due to efficient recombination of carriers in wide band gap solids (eqs. (4) and (5)). Therefore the short-lived deep photoadsorption centers become extremely long-lived immediately after the illumination is switched off. In the absence of tunneling decay of active photoadsorption centers and in the absence of shallow traps, which supply conduction and valence bands by carriers becoming week, only negligibly slow thermal decay (eq. (31)) of active states of photoadsorption center occurs in the dark in the preirradiated solid. Thus, one may assume that the fraction of deep photoadsorption centers may be greater than $\eta$ obtained for an arbitrary fixed irradiation time $t$.

Figure 5 displays the dependence $\eta(t)$ recently obtained for oxygen post-sorption on $\mathrm{ZrO}_{2}$. Earlier, the alike $\eta(t)$ curves for the systems $\mathrm{O}_{2} / \mathrm{CH}_{4} / \mathrm{ZnO}$, 
$\mathrm{O}_{2} / \mathrm{H}_{2} / \mathrm{CH}_{4} / \mathrm{BeO}, \mathrm{O}_{2} / \mathrm{MgO}, \mathrm{O}_{2} / \mathrm{GeO}, \mathrm{O}_{2} / \gamma-\mathrm{Al}_{2} \mathrm{O}_{3}, \mathrm{O}_{2} /$ $\mathrm{Ga}_{2} \mathrm{O}_{3}$ and $\mathrm{O}_{2} / \mathrm{SiO}_{2}$ have been reported [80]. Note, the monotonic limited growth for both $N_{\mathrm{ps}}(t)$ and $N_{\mathrm{ph}}(t)$ quantities (eq. (35)) with the increasing of irradiation time has been observed for all the systems studied. In order to describe the $\eta(t)$ dependence in general case, the formation of the photoadsorbed species (eq. (37)) and their decay (eq. (38)) should be taken into account:

$$
\begin{aligned}
& \mathrm{M}(\text { gas })+\mathrm{S}^{-} \longrightarrow \mathrm{M}^{-} \quad \mathrm{k}_{\mathrm{pha}} \\
& \mathrm{M}^{-}+\mathrm{h} \longrightarrow \mathrm{M}(\text { gas })+\mathrm{S} \quad \mathrm{k}_{\mathrm{r}}{ }^{*}
\end{aligned}
$$

where $\mathrm{k}_{\mathrm{r}}{ }^{*}$ is the recombination constant corresponding to the constant $\mathrm{k}_{\mathrm{r}}$ for (eq. (33)) and $\mathrm{k}_{\mathrm{pha}}$ is the constant for chemical stage of photoadsorption (eq. (37)). Equation (38) describes the photodesorption of adsorbed $\mathrm{M}^{-}$ via recombination with photo holes with apparent first order constant $\mathrm{k}_{\mathrm{des}}=\mathrm{k}_{\mathrm{r}}{ }^{*}[\mathrm{~h}]$. The photodesorption of photoadsorbed oxygen species for $\mathrm{ZrO}_{2}$ has been reported elsewhere [81].

The results of computational modeling of $\eta(t)$ dependence which relates to the mechanism under examination is shown (Figure 6). The generation of electronhole pairs corresponding to fundamental photoelectric absorption has been simulated. In order to describe the formation of the post-sorption species $\mathrm{M}^{-}$ (the pre-irradiation in vacuum and following contact with a gas, $\left[\mathrm{M}^{-}\right]=\left[\mathrm{N}_{\mathrm{ps}}(t)\right]=\left[\mathrm{S}^{-}(\mathrm{vac})\right]$, see eqs. (30), (35), and (37)) the formation and the decay of active states of photoadsorption centers (eqs. (30) and (33) respectively) have been included in the mechanism. The recombination of photo carriers (eqs. (4) and (5)), the formation of color F and V centers (eqs. (6) and (8)) and their recombination decay (eqs. (7) and (9)) respectively, have been also simulated. The concentration of the defects and the rate constants have been fitted so as to satisfy the condition $\left[\mathrm{S}^{-}, \mathrm{F}, \mathrm{S}^{+} \mathrm{V}\right]>10$ [e], 10[h] (eq. (36)) for $t>0.001$ (Figure 6). The decay constant for adsorbed species $\mathrm{k}^{*} \mathrm{r}=0$ (eq. (38)) has been chosen because the photodesorption of photoadsorbed oxygen can be neglected in the case of $\mathrm{O}_{2} / \mathrm{ZrO}_{2}$. Actually, the apparent integrated decay constants, $\mathrm{k}_{\mathrm{d}}$ (eq. (33)) and $\mathrm{k}_{\text {des }}$ (eq. (38)) have been estimated by $(22 \pm 2) \mathrm{s}^{-1}$ [75] and by $(0.03 \pm 0.003) \mathrm{s}^{-1}$ [81] respectively, the UV irradiation of the $\mathrm{ZrO}_{2}$ samples was nearly the same as for the case presented (Figure 5). The condition $\mathrm{k}_{\mathrm{a}} \mathrm{p}$ $\gg \mathrm{k}_{2}$ (eq. (28)) has been accepted in accordance with those in experimental studies (Figure 6). In the latter case the rate of photoadsorption is equal to the rate of active state $\mathrm{S}^{-}$formation and so eq. (37) can be replaced by eq. (30). As the result, the only difference between the apparent decay constant $\mathrm{k}_{\mathrm{d}}=\mathrm{k}_{\mathrm{r}}[\mathrm{h}]$ (eq. (33)) and $\mathrm{k}_{\mathrm{des}}=\mathrm{k}_{\mathrm{r}}{ }^{*}[\mathrm{~h}]$ (eq. (38)) determines the ultimate value of $\eta(t \rightarrow \infty)$ in the model (Figure 6). At the same time the maximum value of $\eta(t \rightarrow 0)=1$. Thus, the low limit of the fraction of deep photoadsorption centers for oxygen in $\mathrm{ZrO}_{2}$ can be estimated by $0.5 \div 0.7$ (figure 5 ). The

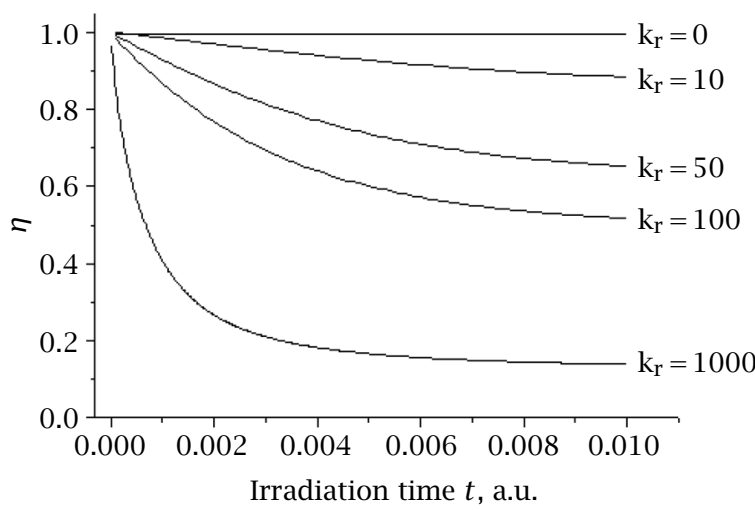

Figure 6. Simulation of the evolution of the post-sorption coefficient $\eta(t)$ dependence along with the changing of the decay constant $\left(\mathrm{k}_{\mathrm{r}}\right)$, corresponding to the active state of photoadsorption center for acceptor molecules.

detailed analysis of the model, which includes the case of multiple photoadsorption centers will be reported [82]. Note, the decreasing of $\eta(t)$ with the increasing of the irradiation time can be also obtained in a frame of multiple centers model, which includes the shallow trap, for some particular case. However, it is not the case of the above considered $\mathrm{O}_{2} / \mathrm{ZrO}_{2}$ system.

The increasing of the "retention time" for the trapped photo carrier due to formation of photoadsorbed species $\left(\mathrm{M}^{-}\right.$, eq. (38)), when compared with the lifetime of active state of photoadsorption center $\left(\mathrm{S}^{-}\right.$, eq. (33)) in vacuum, is also connected with the effect of photoadsorption of small molecules on photo coloration of wide band gap oxides [13, 70]. In general, the electroneutrality condition provides the explanation for the effect. For example, eq. (36) for the case of photoadsorption of acceptor molecules can be expressed as

$$
\mathrm{M}^{-}(\text {gas })+\mathrm{F}(\text { gas })=\mathrm{V}(\text { gas })+\mathrm{S}^{+}(\text {gas })
$$

where $\mathrm{M}^{-}$(gas) is the number of photoadsorbed molecules, while F(gas), $\mathrm{S}^{+}$(gas) and V(gas) are the numbers of photo carriers trapped by corresponding centers. The following conditions can be obtained from eq. (36) (coloration in vacuum) and eq. (39) (coloration a gas) for ultimate cases:

$\mathrm{M}^{-}($gas $)=\mathrm{F}($ gas $)-\mathrm{F}($ vac $)=-\delta \mathrm{F}$ at $\delta \mathrm{V}=0, \delta \mathrm{S}^{+}=0$

and

$$
\mathrm{M}^{-}(\text {gas })=\delta \mathrm{V}+\delta \mathrm{S}^{+} \text {at } \delta \mathrm{F}=0
$$

Actually, the photoadsorption of acceptor gas (oxygen) reduces the efficiency of $\mathrm{F}$ center formation and raises the number of $\mathrm{V}$ centers formed when compared with the photo coloration of wide band gap oxides in vacuum 
Similarly, the photoadsorption of donor molecules on the centers with trapped holes causes the additional formation of F-centers and reduces the number of $\mathrm{V}$ centers created [13, 70]. However, the electroneutrality conditions (eqs. (36) and (39)) say nothing about the magnitude and the sign of the effect for any given gas/solid system within the ultimate cases (eqs. (40) and (41)).

Figure 7 displays the simulated $\delta \mathrm{F}(t)$ and $\delta \mathrm{V}(t)$ kinetic curves for the case of photoadsorption of acceptor gas, all rate constants and defect concentration have been chosen equal to those for the case of $\eta(t)$ simulation (figure 6 ). Thus the bigger the difference between the decay constants $\mathrm{k}_{\mathrm{r}}$ (eq. (33)) and $\mathrm{k}_{\mathrm{r}}{ }^{*}$ (eq. (38)) the more strong is the effect of photoadsorption on photo coloration. No effect occurs at $\mathrm{k}_{\mathrm{r}}=0$, or, in general case, at $\mathrm{k}_{\mathrm{r}}=\mathrm{k}_{\mathrm{r}}{ }^{*}$. Note, in the later case $\eta(t)=$ const $=1$ (figure 6 ). The comprehensive analysis of the effect based on the computational modeling of the mechanism under examination will be also presented [82]. Thus, a few distinctive features of photoadsorption (and photocatalysis) on wide band gap solids such as the LH kinetics of special type (eq. (34)), the dependence of post-sorption coefficient $\eta(t)$ on radiation (pre-irradiation) time (Figure 5), the effect of photoadsorption on photo coloration (Figure 7 , see also [13, 70]) can be described using the notion of active state of photoadsorption (photocatalytic) center.

The lifetime of active center and characteristic pressure for reaction. The lifetime $\tau$ of active states of photoadsorption (photocatalytic) center corresponds to some characteristic pressure: $\mathrm{p}^{*}=(\mathrm{k} \tau)^{-1}$, where $\mathrm{k}$ is the bimolecular gas/solid collision constant corresponding to the constant $\mathrm{k}_{\mathrm{a}}$ (eq. (28)). For collision cross section estimated by squared solid lattice constant $\left(\sim 10^{-15} \mathrm{~cm}^{2}\right)$ for small $(\mu \approx 30$ a.m.u) molecules at $\mathrm{T}=300 \mathrm{~K}$ the characteristic pressure may be presented by: $\mathrm{p}^{*}(\mathrm{~Pa}) \approx 0.01 / \tau\left(\mathrm{s}^{-1}\right)$. The characteristic pressure $\mathrm{p}^{*}$ is rough estimate of the gas pressure needed for observation of the heterogeneous photoreaction involving the photoadsorption (photocatalytic) centers which active states are characterized by the lifetime $\tau$. The most part of the above mentioned photoadsorption centers in their active state are the surface defects with trapped carriers. The lifetime of such active states can be restricted by thermal ionization (shallow centers) (eq. (31)), photoionization (eq. (32)) or recombination with photo carriers of opposite sigh (eq. (33)). Roughly estimated by $\tau=10^{-13} \exp (-\mathrm{E} / \mathrm{kT})$, the lifetime for centers of shallow trap type varies in extremely wide range depending on the position of trapped carrier energy level $\mathrm{E}$ in respect to corresponding band's levels and ambient temperature $\mathrm{T}$. For example, for $\mathrm{E}=20 \mathrm{~kJ} \mathrm{~mol}^{-1}(\approx 0.2 \mathrm{eV})$ at $\mathrm{T}=300 \mathrm{~K}, \tau \approx 10^{-10} \mathrm{~s}$, while for $\mathrm{E}=170 \mathrm{~kJ} \mathrm{~mol}^{-1}$ lifetime is equal to $1.410^{16} \mathrm{~s}$. In the latter case the energy level of thermal trap $(\approx$ $1.7 \mathrm{eV}$ ) is close to the thermal depth of $1 \mathrm{~s}$ level of
F-center in $\mathrm{KBr}$ (see above), while corresponding lifetime is comparable in order of magnitude with the age of Solar system. Thus, the characteristic pressure range for thermal traps is wider than the experimentally available one. The decay time in respect to photoionization of active state of photoadsorption centers can be roughly presented as $\tau=(\sigma \mathrm{I})^{-1}$, where the absorption cross section $\sigma$ for allowed optical transitions can be estimated by $\sim 1 * 10^{-16} \mathrm{~cm}^{2}$. For example, the characteristic pressure range $10^{-4} \div 10^{2}$ Pa corresponds to the photon flux varying within the limits of $10^{14} \div 10^{22}$ photon $\mathrm{cm}^{-2} \mathrm{~s}^{-1}$. In order to estimate the recombination lifetime of surface active centers (eq. (31)) one should know the corresponding recombination cross section and concentration of photo carriers at the surface. The latter depends on different parameters, including the so called rate of surface recombination of carriers, which, typically, is not known. The tentative estimates of the recombination lifetime which is in agreement with that observed for $\mathrm{ZrO}_{2}$ in the pressure range $0.1 \div 10 \mathrm{~Pa}$ have been presented elsewhere [75]. In general, one may conclude that the higher the actual pressure, the much number of short-lived active states of photoadsorption (photocatalytic) centers of different types can manifest themselves in a reaction studied. Note, that the lifetime close to $10^{-7}-10^{-8} \mathrm{~s}$ corresponds to the atmospheric pressure. It will be emphasis in this connection that the wide variety of highly efficient reactions have been observed in the laboratory simulation of atmospheric heterogeneous photoreactions [46]. To elucidate the possible role of such shortlived $\left(10^{-8} \div 10^{-9} \mathrm{~s}\right)$ excitations in heterogeneous photocatalysis on wide band gap solids an application of the high pressure reactors or studies of the photoinduced reactions in polycondensed layers at low temperature is needed. Similar studies have been recently proposed to elucidate possible role of the heterogeneous photocatalysis for abiogenesis in cold dense cosmic dust clouds and at Early Earth [37, 83].

\section{CONCLUSION}

The photoexcitation of surface reactions at wide band gap solids may result from a few different pathways involving photogeneration of excitons or free charge carriers. Possible pathways are connected with fundamental absorption band, with extrinsic/intrinsic defect absorption bands, or with UV-induced color centers bands. Independently of photoexcitation type, active states of the photoadsorption (photocatalytic) centers with trapped electrons and holes far below the fundamental absorption threshold are formed. This allows considering the wide band gap solids $\left(E_{g} \geq\right.$ $3.0 \mathrm{eV}$ ) as potential competitors for the relatively narrow band gap solids in respect to oxidation-reduction photocatalysis. The existence of surface states of 


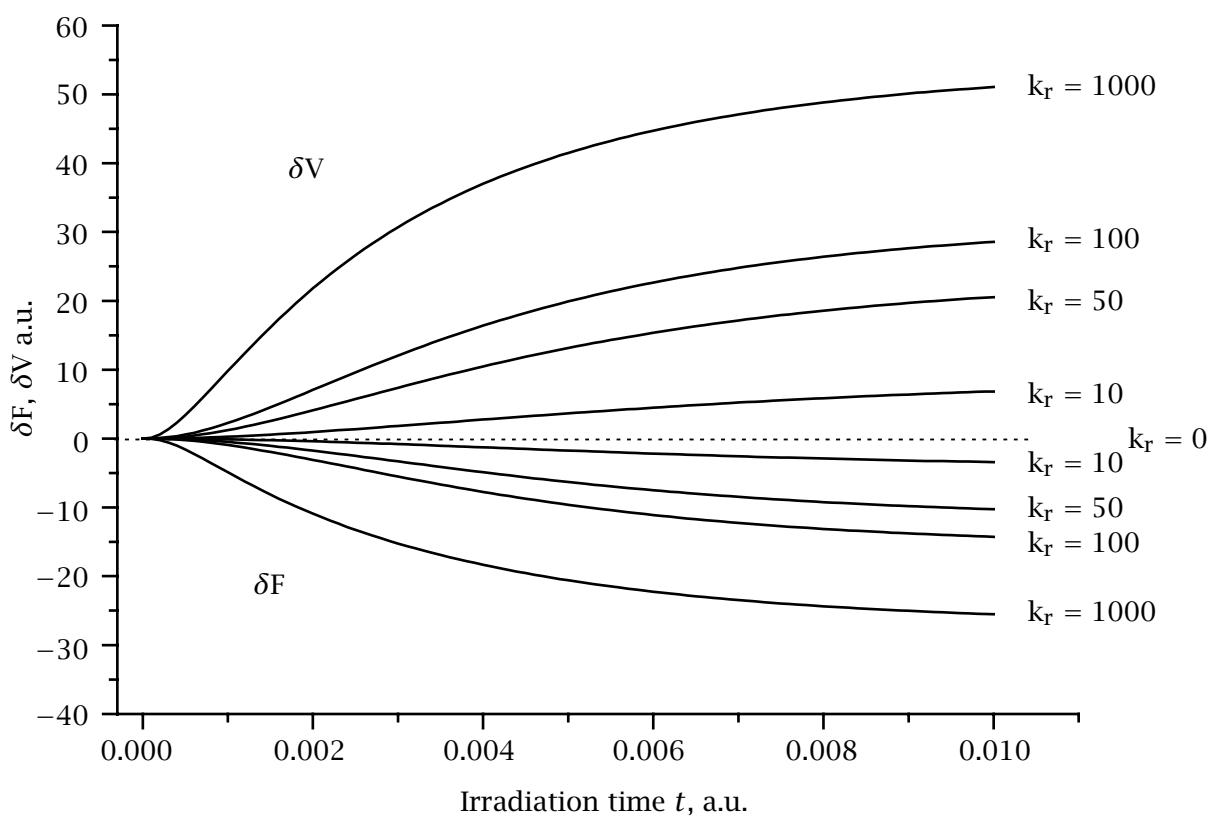

Figure 7. Simulation of the modification of the numbers of photo-induced electron $(\delta \mathrm{F})$ and hole $(\delta \mathrm{V})$ color centers along with the changing of the decay constant $\left(\mathrm{k}_{\mathrm{r}}\right)$, corresponding to the active state of photoadsorption center for acceptor molecules.

different types and strong electron-phonon coupling in ionic wide-band gap solids favor formation of the localized electronic excitations at their surface. These surface excitons can serve as the sensitizers which transfer energy of the electronic excitation to the reagents. Formation of the corresponding complexes between surface excitons and reagents seems highly probable. These complexes would subsequently decay into reaction products or intermediates. Specific pathways of the wide band gap solids photoexcitation are accompanied by formation of the localized surface excitations and active centers, which can be characterized by some lifetime, thus demonstrating resemblance of heterogeneous photocatalysis and photochemistry.

\section{Acknowledgments}

I acknowledge very valuable discussions with Dr. A. V. Emeline (at present, University Concordia, Montreal), with Dr. L. L. Basov (Saint-Petersburg State University) and with Dr. N. G. Petrik (at present, PNNL, Richland, USA). I express cordial thanks to Prof. Nick Serpone (Concordia University, Montreal) for fruitful collaboration we had during last five years. I also gratefully acknowledge stimulating discussions with Dr. V. A. Aleksanian (at present VALTEX International, California), Dr. V. A. Bonch-Bruevich, Dr. L. S. Ershov, and Dr. Yu. K. Dolgikh (Vavilov Institute of Optics, Saint-Petersburg) and with Prof. A. O. Zalensky (University Davis, California). I thank Mrs Svetlana Uvbarkh for her friendly support of this work. I also wish to recall Yurii P. Solonitzyn
(1930-1997) of St. Petersburg State University who inspired and started a lot of the above reviewed studies.

\section{REFERENCES}

[1] N. Serpone and A. V. Emeline, Int. J. Photoenergy 4 (2002), 91.

[2] N. Serpone and E. Pelizzetti (Eds.), Photocatalysis. Fundamentals and Applications, John Wiley \& Sons, New York, 1989.

[3] V. L. Bonch-Bruevich and S. G. Kalashnikov, Physics of Semiconductors, Nauka, Moscow, 1990, in Russian.

[4] J. D. Levine and P. Mark, Phys. Rev. 144 (1966), 751.

[5] E. Garrone, A. Zecchina, and F. S. Stone, Philos. Mag. B 42 (1980), 683.

[6] P. V. Sushko and A. L. Shluger, Surface Science 421 (1999), L157.

[7] G. Baldini and B. Bosacchi, Phys. Rev. 166 (1968), 863.

[8] B. W. Fowler (Ed.), Physics of Color Centres, Academic Press, N-Y, London, 1968.

[9] A. M. Stoneham, Theory of Defects in Solids. Part 2. Clarendon Press, Oxford, 1975.

[10] M. Sterrer, T. Berger, O. Diwald, and E. Knozinger, J. Am. Chem. Soc. 125 (2003), 195.

[11] V. L. Vinetskii and G. A. Kholodar, Statistical Interaction of Electrons and Defects in Semiconductors, Naukova Dumka, Kiev, 1969, in Russian.

[12] R. H. Bube, Photoconductivity of Solids, John Wiley \& Sons, New York, 1960. 
[13] V. K. Ryabchuk and G. V. Burukina, Sov. J. Phys. Chem. 65 (1991), 1621.

[14] A. Emeline, A. Salinaro, V. K. Ryabchuk, and N. Serpone, Int. J. Photoenergy 3 (2001), 1.

[15] V. K. Ryabchuk, L. L. Basov, and Yu. P. Solonitzyn, Sov. Chem. Physics 8 (1989), 1475.

[16] A. Gedanken, J. Jortner, B. Raz, and A. Szike, J. Chem. Phys. 57 (1972), 3456.

[17] R. M. Pearlstein, Photochem. Photobiol. 35 (1982), 835.; A. S. Davydov, Biology and Quantum Mechanics, Pergamon Press, NY, 1982.

[18] E. I. Rashba and M. D. Sturge (Eds.), Excitons, Selected Chapters, Elsevier, Amsterdam, 1987, 273.

[19] V. M. Agranovich, M. D. Galanin, and M. D., Electronic Excitation Energy Transfer in Condensed States, Nauka, Moscow, 1978, in Russian.

[20] K. S. Song and R. T. Williams, Self-Trapped Excitons, Springer, Berlin, 1996, p. 281.

[21] A. Lushchik, M. Kirm, Ch. Lushchik, I. Martinson, and G. Zimmerer, J. Luminescence 87-89 (2000), 232.

[22] J. Song, R. VanGinhoven, L. Corrales, and H. Johnsson, Faraday Discuss. 117 (2000), 303.

[23] Ch. Lushchik and A. Lushchik, Decay of Electronic Excitations with Defect Formation in Solids, Nauka, Moscow, 1991, in Russian.

[24] J. Phys. Chem. Solids, (Special Issue) 51 (1990), 7.

[25] C. Chen and H. Meng, Phys. Rev. B 64 (2001), 125202.

[26] Y. K. Voron'ko, V. V. Osiko, and I. A. Shcherbakov, Proc. Acad. Sci. USSR, Physics 46 (1982), 970, in Russian.

[27] A. I. Burshtein, Sov. Phys. LETP 35 (1972), 882.

[28] M. Takeuchia, H. Yamashita, M. Matsuoka, M. Anpo, T. Hirao, N. Itoh, and N. Iwamoto, Catalysis Letters 67 (2000), 135.

[29] J. H. De Boer, Zs. phys. Chem. 21 (1933), 208.

[30] A. N. Terenin, Sov. J. Phys. Chem. 6 (1936), 189.

[31] I. Harrison, J. C. Polanyi, and P. A. Young, J. Chem. Phys. 89 (1988), 1475.

[32] K. Ya. Kasparov and A. N. Terenin, Acta Phys. Chem. USSR 15 (1941), 343.

[33] V. A. Kotelnikov, A. N. Terenin, Reports Acad. Sci. USSR 174 (1967), 1366, in Russian.

[34] L. L. Basov, A. N. Terenin, and Yu. P. Solonitzyn, Reports Acad. Sci. USSR 164 (1965), 122, in Russian.

[35] L. L. Basov, G. N. Kuzmin, I. M. Prudnikov, and Yu. P. Solonitzyn, Adv. Photonics, F. I. Vilesov (Eds.), Leningrad State University, Leningrad 6 (1976), 82, in Russian.

[36] L. L. Basov, Yu. P. Efimov, and Yu. P. Solonitzyn, Adv. Photonics, F. I. Vilesov (Eds.), Leningrad State University, Leningrad 4 (1974), 12, in Russian.

[37] A. V. Emeline, V. A. Otroshchenko, V. K. Ryabchuk, and N. Serpone, J. Photochem. Photobiol. C. 3 (2003), 203.

[38] V. K. Ryabchuk, Catalysis Today 58 (2000), 89.
[39] L. L. Basov, V. K. Ryabchuk, and Yu. P. Solonitzyn, React. Kinet. Catal. Lett 39 (1989), 331.

[40] L. L. Basov, Ph.D. Thesis, Leningrad State University, 1971.

[41] V. S. Zakharenko, A. E. Cherkashin, N. P. Keier, and G. F. Gerasimova, Proc. Institute of Catalysis, Acad. Sci. USSR 4 (1974), 32, in Russian.

[42] V. N. Kuznetsov and A. A. Lisachenko, Sov. J. Phys. Chem. 6 (1991), 1568.

[43] A. V. Emelin, G. N. Kuzmin, D. Purevdorj, and I. G. Shenderovich, Russ. Kinet. Catal. 38 (1997), 446, in Russian.

[44] A. V. Emeline, V. K. Ryabchuk, and N. Serpone, J. Phys. Chem. 103 (1999), 1316.

[45] A. V. Emeline, G. N. Kuzmin, D. Purevdorj, V. K. Ryabchuk, and N. Serpone, J. Phys. Chem. 103 (1999), 1316.

[46] V. N. Parmon and V. S. Zakharenko, CATTECH 5 (2001), 96.

[47] A. V. Emeline and N. Serpone, J. Phys. Chem. 106 (2002), 12221.

[48] A. M. Volodin, Catalysis Today 58 (2000), 103.

[49] S. L. Kaliaguine, B. N. Shelimov, and V. B. Kazansky, J. Catal. 55 (1978), 384.

[50] G. N. Kuzmin, M. V. Knatko, and S. V. Kurganov, React. Kinet. Catal. Lett. 23 (1983), 313.

[51] Yu. M. Artemiev and G. N. Kuzmin, Bulletin of Saint-Petersburg State University, Physics, Chemistry. 4 (1996), 50, in Russian.

[52] M. Anpo, Y. Yamada, S. Coluccia, A. Zecchina, and M. Che, J. Chem. Soc. Faraday trans. I 85 (1989), 609.

[53] B. N. Shelimov and B. B. Kasansky, in Photocatalytic Conversion of Solar Energy, (K. I. Zamaraev and V. N. Parmon, Eds.), Nauka, Novosibirsk, 1991, 109, in Russian.

[54] J. H. Crawford, Semiconductors Insulators 5 (1983), 599.

[55] M. A. Monge, R. Gonzalez, J. E. Munoz Santiuste, R. Pareja, Y. Chen, E. A. Kotomin, and A. I. Popov, Nucl. Instr. and Meth. in Phys. Res. B 166, 167 (2000), 220.

[56] N. G. Petrik, A. B. Aleksandrov, and A. I. Vall, J. Phys. Chem. B 105 (2001), 5935.

[57] V. I. Korotkov and V. E. Kholmogorov, Excited Molecules. The Kinetics of Transformations, (A. A. Krasnovsky, Ed.), Nauka, Leningrad, 1982, p. 176, in Russian.

[58] L. L. Basov, Yu. P. Solonitzyn, and V. K. Ryabchuk, React. Kinet. Catal. Lett. 32 (1988), 119.

[59] Yu. P. Solonitzyn, L. L. Basov, and V. K. Ryabchuk, Sov. J. Phys. Chem. 54 (1980), 2624.

[60] E. P. Mesheryakov, A. V. Emelin, T. S. Minakova, and V. K. Ryabchuk, Sov. Kinet. Catal. 33 (1992), 581.

[61] A. V. Alexandrov, E. D. Aluker, I. A. Vassiliev, A. F. Nechaev, and S. A. Chernov, Introduction into Radiation Physics and Chemistry of Surface of Alkali 
Halide Crystals, Zinatne, Riga, Latvia, 1989, in Russian.

[62] E. D. Aluker, D. Yu. Lusis, and S. A. Chernov, Electronic Excitation and Radialuminescence of Alkali Halide Crystals. Zinatne, Riga, Latvia, 1979, in Russian.

[63] Yu. P. Solonitzyn and A. N. Terenin. Disc. Farday. Soc. 28 (1959), 28.

[64] E. P. Mesheryakov, A. V. Emelin, T. S. Minakova, and V. K. Ryabchuk, Sov. J. Phys. Chem. 66 (1992), 1387.

[65] A. V. Emelin and V. K. Ryabchuk, Sov. J. Phys. Chem. 72 (1998), 512.

[66] A. V. Emeline, S. V. Petrova, V. K. Ryabchuk, and N. Serpone, Chem. Mater. 10 (1998), 3484.

[67] V. N. Kuznetsov, F. I. Vilesov, and A. A. Lisachenko, Proc. Acad. Sci. USSR 222 (1975), 1373.

[68] G. V. Burukina, G. K. Vitkovsky, and V. K. Ryabchuk, Bulletin of Saint-Petersburg State University, Physics, Chemistry 4 (1990), 92, in Russian.

[69] A. V. Emeline, private communication.

[70] A. V. Emeline, G. V. Kataeva, V. K. Ryabchuk, and N. Serpone, J. Phys. Chem. B 103 (1999), 9190.

[71] M. M. Mikhailov, M. I. Dvoretsky, and N/Y. Kuznetsov, Sov. Inorg. Mater. 20 (1984), 449.

[72] G. V. Burukina, Ph. D. Thesis, Leningrad State University; Leningrad, USSR, 1990.
[73] V. L. Rapoport, B. M. Antipenko, M. G. Malkin, and M. G. SoV, J. Kinet. Catal. 9 (1968), 1306.

[74] Yu. I. Aristov, V. N. Parmon, and K. I. Zamaraev, React. Kinet. Catal. Lett. 27 (1985), 245.

[75] A. V. Emeline, A. V. Rudakova, V. K. Ryabchuk, and N. Serpone, J. Phys. Chem. B 102 (1998), 10906.

[76] N. Serpone, A. Salinaro, A. V. Emeline, and V. K. Ryabchuck, J. Photochem. Photobiol. A 130 (2000), 83.

[77] A. V. Emeline, V. K. Ryabchuk, and N. Serpone, J. Photochem. Photobiol. A 133 (2000), 89.

[78] Y. Ohko, K. Hashimoto, and A. Fujishima, J. Phys. Chem. A 101 (1997), 8057.

[79] A. Fujishima, Tata N. Rao, and Donald A. Tryk, J. Photochem. Photobiol. C 1 (2000), 1.

[80] Yu. P. Solonitzyn, I. M. Prudnikov, and V. M. Yurkin, Russ. J. Phys. Chem. 57 (1982), 2028.

[81] A. V. Emeline, V. M. Khudnev, and V. K. Ryabchuk, Bulletin of Saint-Petersburg State University, Physics, Chemistry 4 (1999), 23, in Russian.

[82] S. A. Polikhova, N. S. Andreev, A. V. Emeline, V. K. Ryabchuk, and N. Serpone, submitted to J. Phys. Chem., 2003.

[83] V. A. Otroshchenko, V. A. Alekseev, and V. K. Ryabchuk, Russ. Adv. In Biochemistry 42 (2002), 295. 


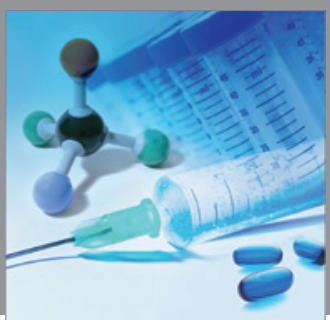

International Journal of

Medicinal Chemistry

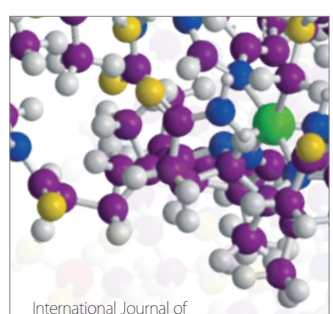

Carbohydrate Chemistry

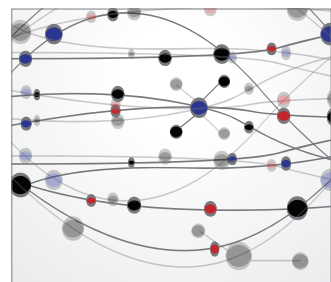

The Scientific World Journal
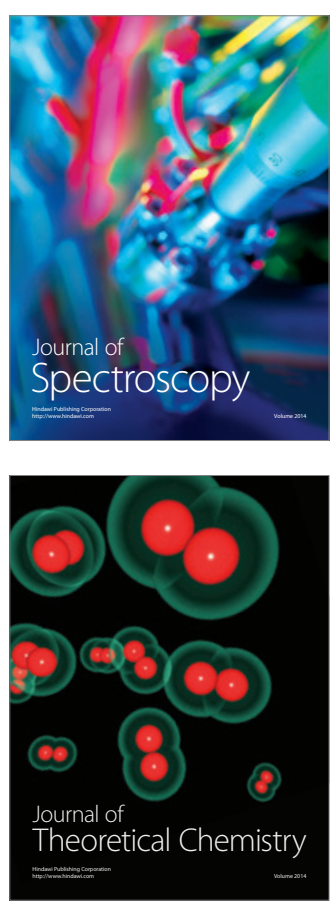
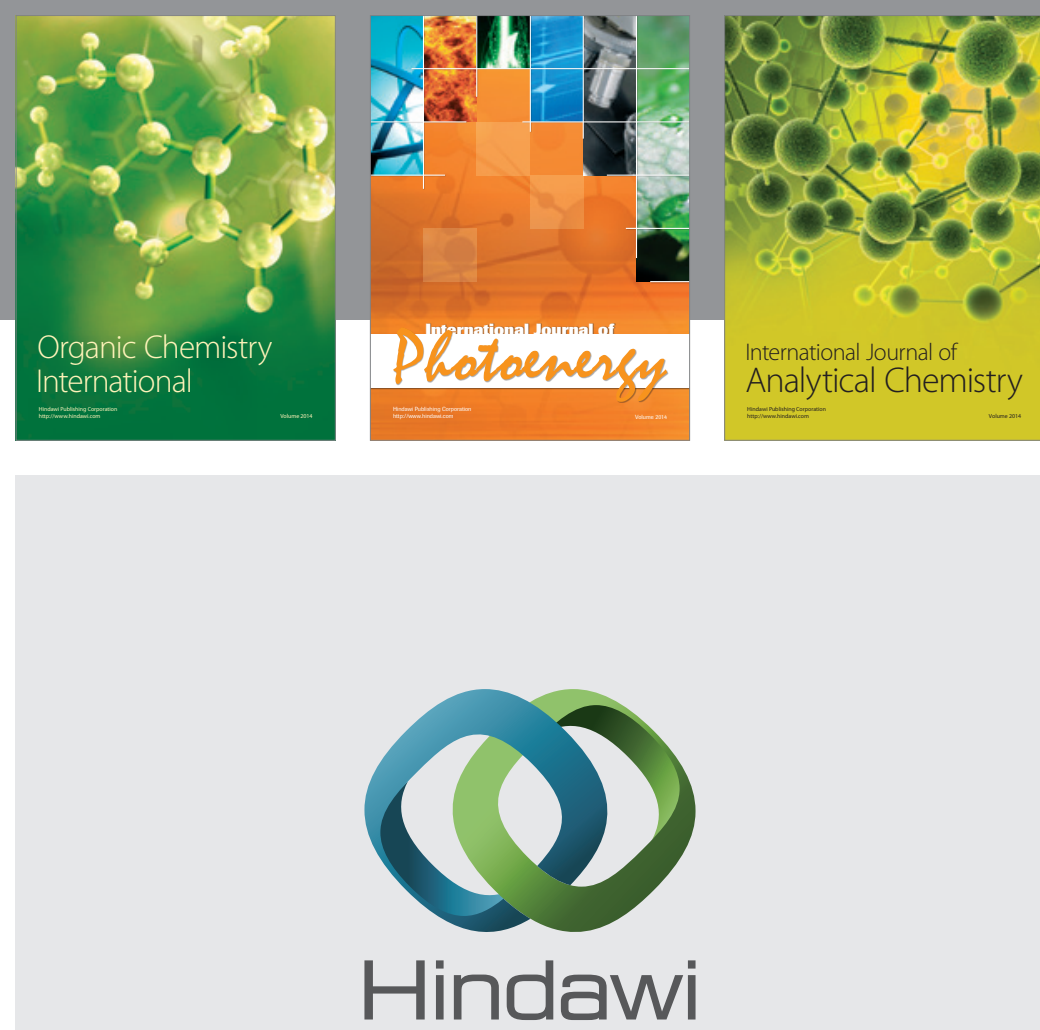

Submit your manuscripts at

http://www.hindawi.com
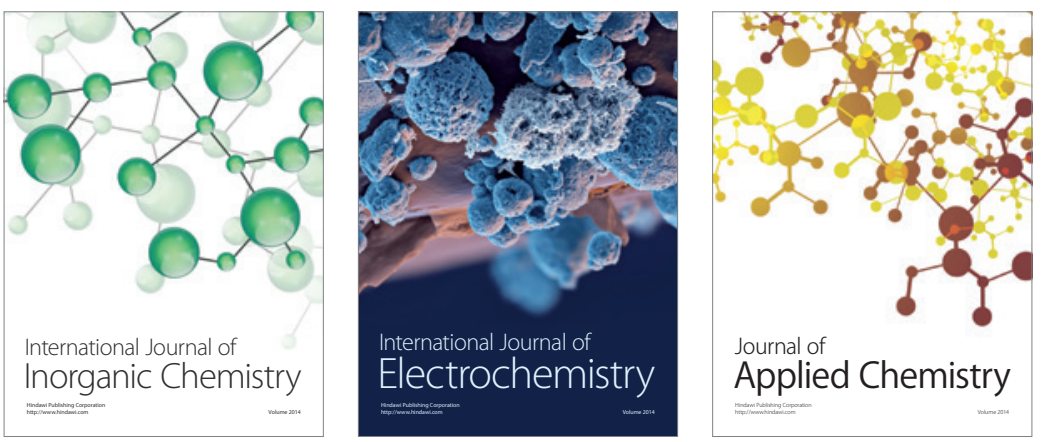

Journal of

Applied Chemistry
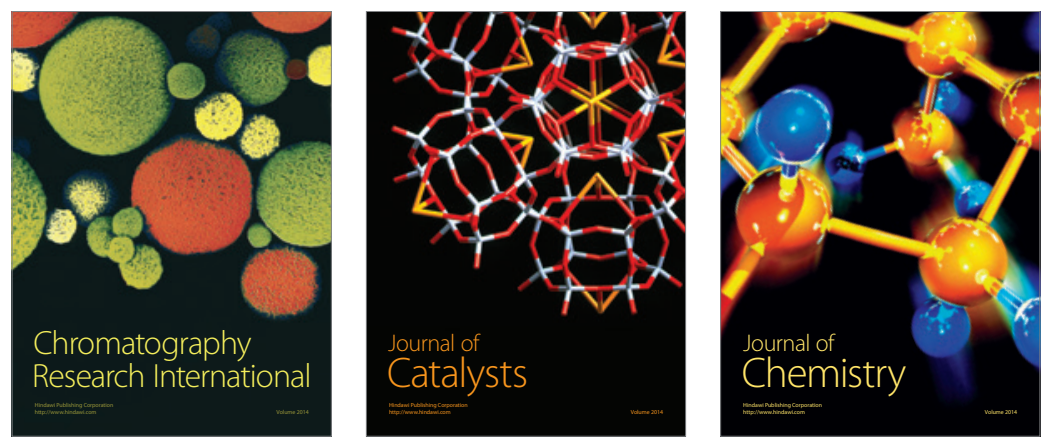
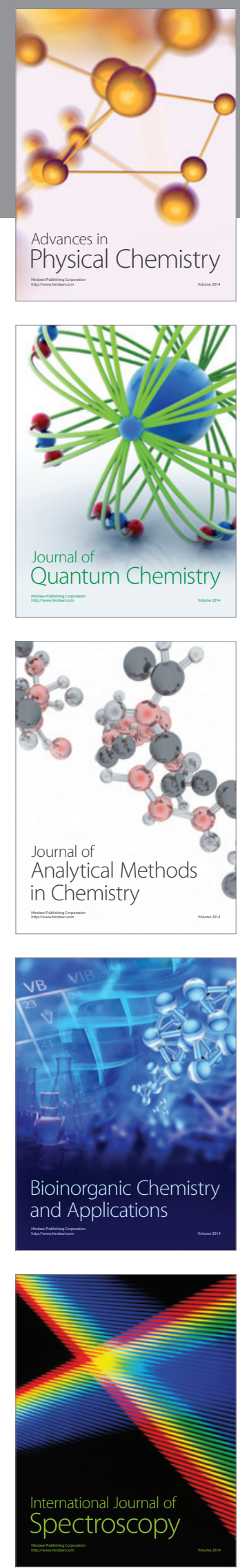